\section{Análisis estratigráfico en la muralla medieval de Marchena (Sevilla)}

\section{Stratigraphical analysis of Marchena's medieval wall (Seville)}

TANIA BELLIDO MÁRQueZ

Universidad Pablo de Olavide. Sevilla*

\begin{abstract}
Resumen
En este artículo presentamos la evolución histórica-constructiva que ha experimentado la muralla medieval de Marchena a lo largo de los siglos, partiendo del análisis estratigráfico efectuado en los lienzos más significativos correspondientes a las puertas del conjunto que aún permanecen en pie, así como de los resultados obtenidos en la intervención arqueológica del sector nororiental del recinto de la Alcazaba.
\end{abstract}

Palabras claves: cerca, arqueología, alzado, excavación, tardoalmohade, tapial, cristiano, reformas, alcazaba, barbacana.

\section{Abstract}

The historical-constructive evolution of Marchena's medieval wall throughout yhe centuries is here analysed. The results are based on the stratigraphic analysis of most significant walls still standing with their corresponding doors and the archaeological excavation in the northeastern sector of the enclosure of the fortress.

Key words: wall, archaeology, standing wall, exacavation, late Almohad, tapial (rammed earth), Christian, reforms, citadel, barbican.
En este trabajo presentamos los resultados de los primeros análisis estratigráficos efectuados en los tramos más notables de la muralla medieval de Marchena (Sevilla); el fin más específico de nuestra investigación consistió en establecer una secuencia crono-estratigráfica con la intención de comprender la evolución constructiva que ha ido experimentando a lo largo de los siglos esta cerca, dentro de un amplio contexto histórico-arqueológico y teniendo como principal base las labores de campo efectuadas en el sector nororiental.

Sin embargo, dichas labores no se extendieron a la totalidad de la muralla, sino que se centraron en una amplia zona de unos $90 \mathrm{~m}$ de longitud pertenecientes al recinto de la Alcazaba así como parte del recinto del Parque. Por tanto, nuestro objetivo consistió, no sólo en analizar estratigráficamente dicho sector excavado, sino ampliar nuestra intervención por otros alzados que aportarían datos no menos relevantes (aunque siempre bajo la premisa de ausencia total de excavación).

\section{CONTEXTO HISTÓRICO}

Marchena se ubica en pleno Valle del Guadalquivir, concretamente sobre su margen derecha y es regada por uno de sus afluentes, el río Corbones y por varios arroyos. Esta comarca presenta una ventajosa posición, a tan sólo $59 \mathrm{Km}$ de Sevilla y a $90 \mathrm{Km}$ de Córdoba. Su término municipal se fija en $379 \mathrm{~km}^{2}$ y cuenta con una población actual que ronda los 20.000 habitantes.

Su orografía es fundamentalmente llana, aunque destacan algunos enclaves con una altitud media de unos 150 m.s.n.m., como es el caso de los cerros de La Mota ${ }^{1}$, San Agustín y San Miguel. Esta elevada posición, junto con la disponibilidad de agua y la productividad de sus tierras, hacen que se convierta en un lugar idóneo para asentamientos desde época prehistórica (Millán, 1996, 18).

Marchena, cuyo topónimo actual deriva del nombre árabe Maršāna, cuenta con uno de los más extensos y mejor conservados sistemas defensivos islámicos de toda la provincia, en la que han perdurado otros tres, el de Carmona, Écija y Sevilla (VALOR, 2004, 146-147). Muchos de sus lienzos han permanecido en pie gracias a que han sido adaptados en construcciones más modernas, o incluso se han utilizado como asiento para nuevas edificaciones.

Esta cerca fue construida en época tardoalmohade, en la que observamos una utilización constante del tapial

\footnotetext{
${ }^{1}$ Sobre el que se funda la antigua ciudad medieval y desde donde es posible divisar Carmona, así como las tierras circundantes.
} 


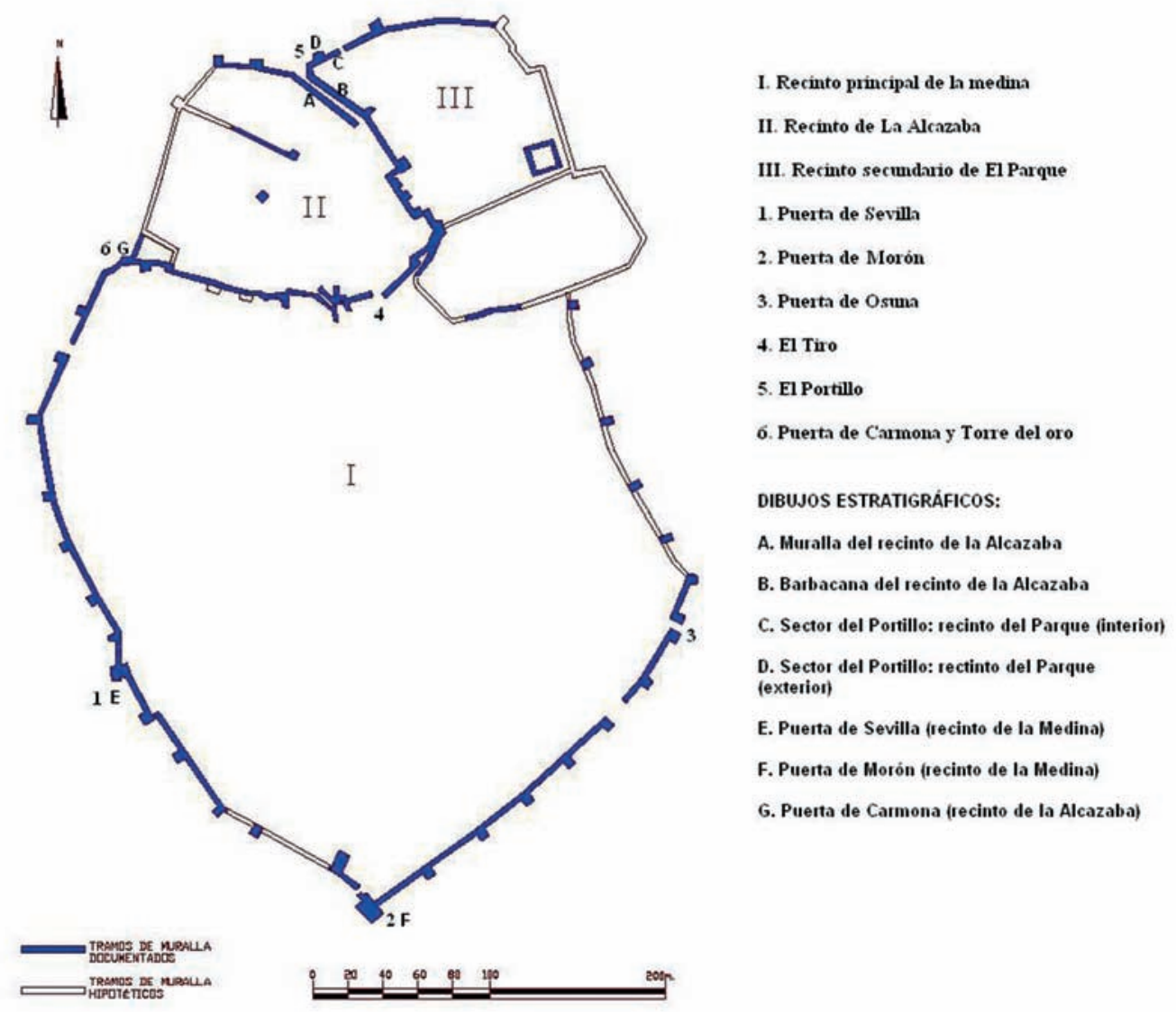

Fig. 1. Plano de la muralla de Marchena. A partir de Ravé $(1993,56)$

simple como técnica constructiva con algunas inserciones decorativas de hileras de ladrillos y torres cuadrangulares ${ }^{2}$ dispuestas in extenso por todo el recinto, que debido a reformas posteriores coexisten con torreones semicirculares realizados en cantería, fábrica muy utilizada también para añadidos sobre ciertos lienzos. La cerca organiza tres recintos (Fig. 1):

— Recinto de "La Alcazaba»: donde se encontraba la antigua $A l-q a s a b a$, de la que no se conserva absolutamente nada $^{3}$. Actuaba como centro administrativo de la medina y se ubicaba en la zona más elevada de Marchena (La Mota), contando con una muralla propia de traza más o menos elíptica independiente de la muralla de la Madina, más reforzada y con mayores proporciones, desde donde se controlaba militarmente los disturbios producidos en el interior de la medina, así como los asaltos procedentes del exterior. De igual forma, se encontraba

${ }^{2}$ Con una distancia media entre ellas de unos 30 ó $40 \mathrm{~m}$, y unas dimensiones de $5 \times 5$ y $5 \times 6 \mathrm{~m}$.

${ }^{3}$ Aunque el basamento de la torre de la Iglesia de Santa María (Ravé, 1993, 207), así como la presencia de muros y bastiones junto a la cabecera de la iglesia (Amores et alii, 1985, 11), podrían pertenecer a la antigua alcazaba. protegida por una barbacana de la que se observan escasos vestigios en el sector nororiental y que tan sólo hemos documentado en este recinto. Ambas estructuras contaban con una serie de torres que se presentan en su mayoría bastante derruidas.

Este recinto contaba con una modesta superficie irregular, a la que se accedía, según las investigaciones, por dos puertas: «Arco del Tiro de Santa María» y la «Puerta de Carmona».

- Recinto de la Madina: en el que se desarrolla la Madina, rodeada por una muralla de trazado tendente a la forma oval. La medina ocupaba lo que es en la actualidad el barrio de San Juan, a la que se podía acceder mediante una serie de puertas de acceso o salida que comunicaban con los caminos más próximos que llevaban a las ciudades principales. Estaban distribuidas a lo largo de todo el perímetro, y tanto la de Sevilla (o Arco de la Rosa), como la de Morón (o Los Cuatro Cantillos), se conservan en buen estado debido a las numerosas reformas a las que han sido sometidas a lo largo de su historia.

De la «Puerta de Osuna» se conoce su primitivo aspecto gracias a un dibujo de principios del siglo XX. 
Realizado por la Comisión de Monumentos, presentaba dos torreones cuadrangulares de los que tan sólo conservamos el de la izquierda, de fábrica de tapial almohade, donde se abrió en 1882 un vano de medio punto para albergar en un altar a una virgen (ALCAIDE, 2003, 90, 91); de la torre derecha, sólo quedan escasos restos dentro de las viviendas. De la «Puerta de Écija» (también llamada de las «Torres Caídas»), que al parecer servía de elemento de unión entre la cerca de la medina y el recinto del Parque, no se conoce su ubicación exacta.

- Recinto secundario: conocido como recinto de «El Parque», construido después de la muralla, pero adscrito a un momento islámico final o cristiano inicial y al que se accede a través de un arco apuntado conocido como «El Portillo». Se destruyó una parte de su lienzo para la construcción de la C-339. Conserva una gran alberca que abastecía de agua el área de la Mota y que posteriormente, a mediados del siglo XVII, se convirtió en parque de recreo. De igual manera, estaba fortificado y se presentaba adyacente al recinto de «La Alcazaba» por su costado nordeste.

\section{ESTUDIOS ESTRATIGRÁFICOS}

El sistema que hemos seguido toma como referencia las experiencias recogidas por Miguel Ángel Tabales en su propia tesis doctoral (TABALES, 1998) en la que se propone un claro sistema de trabajo encaminado al desarrollo de este tipo de actuaciones. Nuestros estudios estratigráficos se centrarán en diversos alzados repartidos por los tres recintos que organiza la muralla marchenera ${ }^{4}$.

— Recinto de la Alcazaba: muralla y barbacana. Nos centraremos en el tramo en el que hemos tenido la oportunidad de excavar, es decir, en el sector nororiental.

- Recinto secundario del Parque: entorno del Portillo. Realizaremos el análisis de esta zona, tanto por su costado norte como sur, lugares en los que también hemos excavado.

- Recinto de la Madina: Puerta de Sevilla, Puerta de Morón y Puerta de Carmona junto a la torre albarrana que la flanquea (Torre del Oro). Abordaremos el estudio de los alzados principales de algunas puertas de este recinto que daban acceso a los caminos que conducían a las ciudades más importantes.

${ }^{4}$ No todos los procesos advertidos están presentes en todos los tramos de muralla analizados.
Los estudios de paramentos se ejecutaron en dos niveles consecutivos de actuación (TABALES, 1997, 7175). En un primer lugar, se auscultaron las estructuras a través de las siguientes operaciones: obtuvimos un fichero completo donde quedó reflejado el estado previo del edificio antes de nuestra investigación, fijando nuestra atención, fundamentalmente, en muros, vanos, detalles decorativos, etc.; luego, identificamos numéricamente los sectores y los "paramentos guía»; seguidamente, hicimos el análisis de los distintos tipos de adosamientos (simples, con encastres simples o complejos, coetáneos, etc.). Esto fue acompañado de una simbología que se ha creado para tal fin, distinguiendo paramentos coetáneos, encastrados o adosamientos simples. El orden de los adosamientos y su tipología definen los procesos constructivos del palimpsesto. La comprensión de todo ello es básico para comenzar a tener un dictamen sistemático de la evolución del monumento.

Para la realización de esta lectura inicial, accedimos a la fábrica de los muros en las zonas de unión, y después pudimos identificar las «divisiones edilicias generales»; es decir, procedimos a rellenar sobre un dibujo de alzado con las unidades paramentales guía aquellos componentes fundamentales del muro: tapiales, ladrillo, piedra, etc.

Una vez concluidos ambos estudios (el de adosamientos y el de identificación de fábricas esenciales), pudimos establecer las primeras hipótesis de partida, las cuales se plasmaron en una planta secuenciada, en la que se otorgó a cada fase una trama distinta, acompañada de una matriz interpretativa con la secuencia cronológica provisional.

En segundo lugar, el siguiente nivel de actuación fue la fase de investigación, en la que se cumplimentaron varios «ficheros de control arqueológico». Consecutivamente, tras la catalogación, se realizaron los estudios paramentales sistemáticos. A nuestro entender existen dos vías de lectura de alzados: una con carácter estratigráfico y finalidad evolutiva derivada de los estudios arqueológicos tradicionales, pero sobre todo desarrollada desde la aplicación del método Harris (PARENTI, 1988); y otra con carácter analítico estructural, con finalidad descriptiva, tipológica y patológica (DogLIONI, 1988).

Nosotros hemos optado por la absorción de las distintas vías, vinculándolas al resto de actuaciones arqueohistóricas bajo una misma óptica y finalidad, asumiendo los fundamentos evolutivos, tipológicos, estructurales, etc., cuyo fin esencial es la valoración histórica de la estructura. 

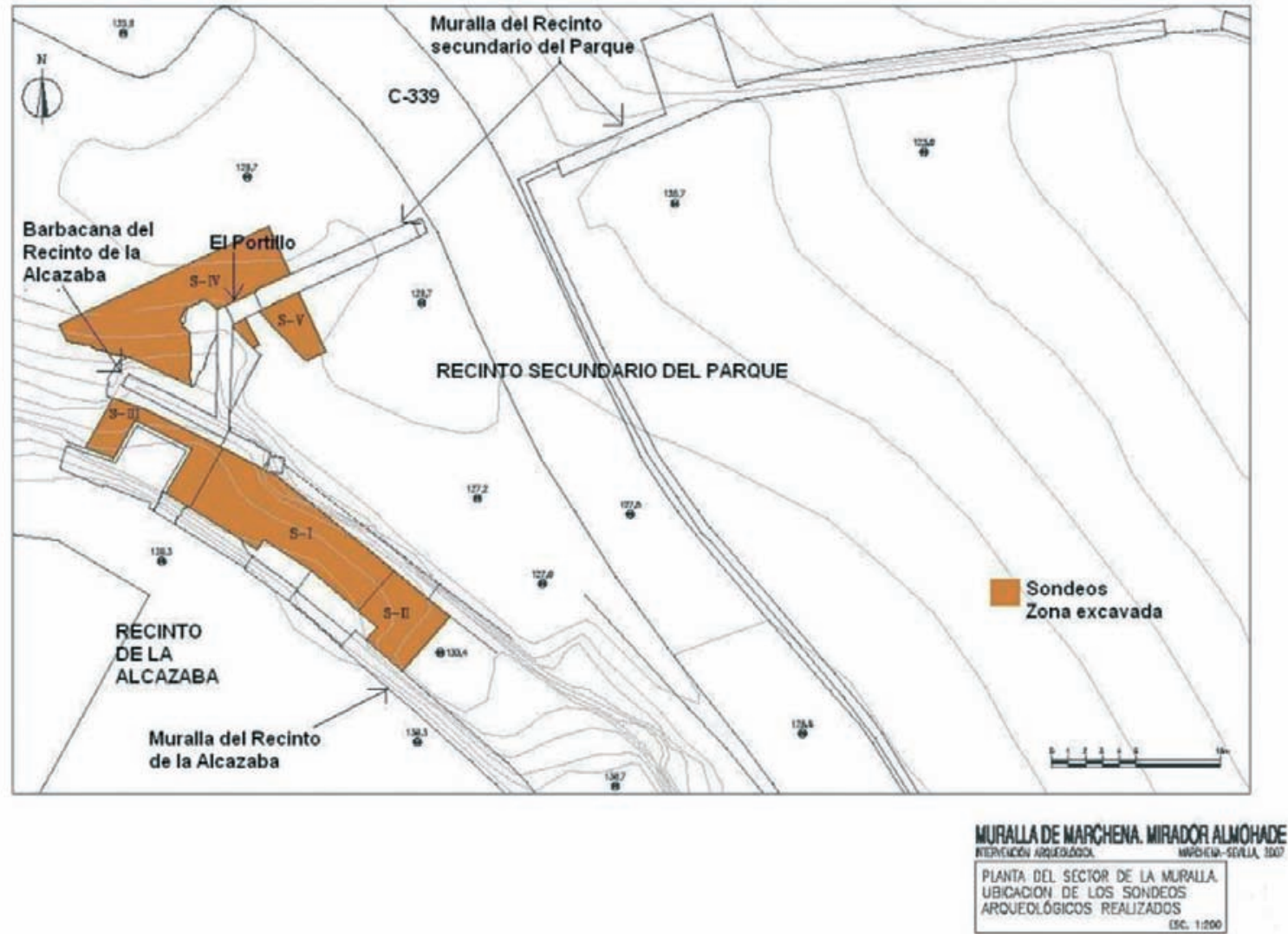

Fig. 2. Planta del sector nororiental del recinto de la Alcazaba. Ubicación de los sondeos arqueológicos realizados

\section{Muralla del recinto de la Alcazaba (sector nororiental) ${ }^{5}$ (Fig. 2 y 3 )}

\section{PROCESO 1. Pre-almohade (I). Terreno natural}

La excavación efectuada en este tramo concluyó en un estrato conformado por un tipo tierra limosa amarillenta (U.E. 30) propia del período Andaluciense Regresivo, de hace unos 5 ó 6 millones de años, momento en el que el mar que cubría esta villa se retira, dejando este sedimento tan característico en Marchena (Ternero, 2006, 56-57). En este relleno aparecían incrustadas grandes formaciones inclinadas de piedra (U.E. 31) que podrían tratarse de la roca madre.

Éstas aparecían recubiertas por otro paquete menos puro que el anterior, al aparecer entremezclado con otra tierra más oscura y arenosa. En él se hallaron abundantes

\footnotetext{
5 En el caso concreto de los análisis murarios del sector de la Alcazaba y un tramo del recinto de El Parque donde excavamos, tuvimos la posibilidad de llevar a cabo el estudio en tres niveles distintos:

a) Estratigráfico: donde hemos datado, valorado y advertido los procesos experimentados en cada alzado.

b) Tipológico: mediante un código creado al efecto, hemos identificado tipos de aparejo, vanos, enlucidos y añadidos.

c) Constructivo: hemos constatado las relaciones físicas más importantes: análisis de adosamientos, rupturas estructurales o superficiales, grietas..
}

fragmentos cerámicos calcolíticos, a excepción de un galbo romano $^{6}$, que podría tratarse de alguna intrusión.

Por tanto, todo ello conduce a una ampliación de los conocimientos existentes sobre los antecedentes históricos de esta localidad, sobre los que se podría decir, tras las excavaciones efectuadas, que Marchena reveló una indiscutible ocupación prehistórica en la era calcolítica, habida cuenta de la gran cantidad de materiales cerámicos exhumados de esa época.

\section{Proceso 3. Primer período tardoalmohade. Construcción de la muralla}

El recinto amurallado de la Alcazaba se sitúa sobre el promontorio de la Mota, hecho que favorece su protección y defensa (TORRES, 1985, 455). Su construcción sobre este terreno tan irregular dificultó el proceso de cimentación; hubo que nivelarlo mediante una base suficientemente reforzada.

Para tal fin, se comenzó a colmatar el terreno con rellenos de tierra hasta crear un sólido asiento ${ }^{7}$ sobre el cual

${ }^{6}$ Cerámica común romana (siglos I-II d.C.) que conserva restos de mortero adherido (Fournier, 2008).

${ }^{7}$ Conformado por rellenos de tierra compactados con nódulos de cal y cuñas de mampuestos. 


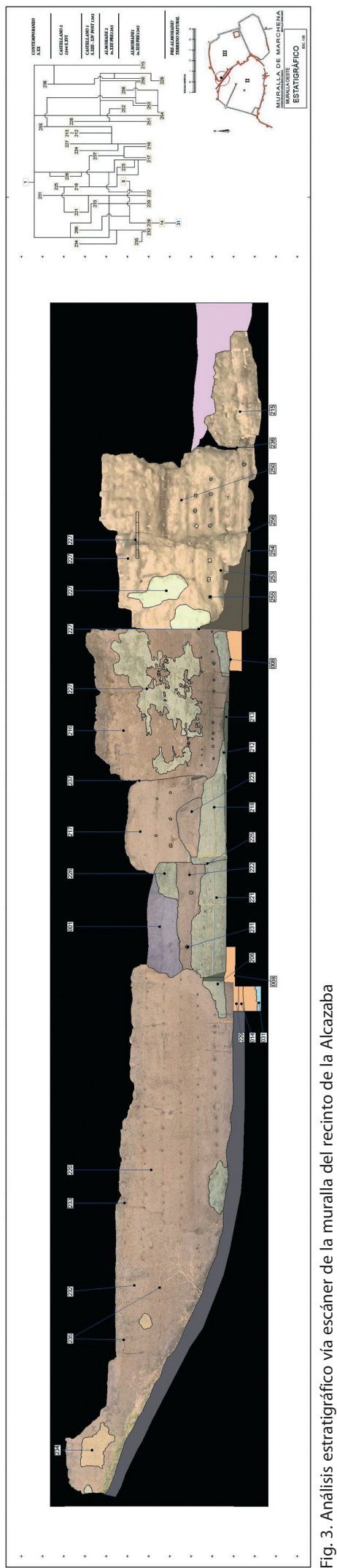

se creó una doble zapata (U.E. 14, U.E. 229), la superior más ancha que la inferior, en la que se sustenta la muralla, y que se cubrieron con capas de tierras separadas por tongadas de cal hasta llegar al nivel de liza almohade (U.E. 8) a una altura de $133^{\prime} 48$ m.s.n.m.

La técnica constructiva empleada en los lienzos es a base de cajones de tapial simple ${ }^{8}$. El uso de la tabiya islámica, heredera del opus caementicium romano, se comienza a extender en el período almohade (TABALES, $2004,85)$ y reemplaza a los muros de piedra, fundamentalmente en arquitectura militar (TABALES, 2000, 1083) (Fig. 4) $)^{9}$.

Algunos de los antiguos mechinales que se observan a lo largo de toda la fábrica constructiva, presentan como novedad restos de las antiguas tablas de madera que utilizaron para la realización de los cajones de tapial.

\section{Proceso 5. Fase inicial castellana. Reformas en los siglos $X I V-X V$}

Cuantiosas e importantes fueron las reformas cristianas que experimentó la muralla, aunque no en este alzado. No obstante, sufrió deterioros importantes que supusieron una serie de arreglos durante siglos.

En este período, tan sólo destacar la pérdida de consistencia del antiguo tapial almohade, que comienza a resentirse provocando considerables grietas.

Sin embargo, la cerca de la medina percibió notables cambios, fundamentalmente en las puertas que daban a los caminos que conducían a las ciudades más importantes, tal es el caso de la puerta de Sevilla o Arco de la Rosa, así como la puerta de Morón o de los Cuatro Cantillos. Éstas fueron renovadas con mampostería, adquiriendo un aspecto más monumental.

\section{Proceso 6. Segunda fase castellana. Reformas en el siglo XVI}

Aunque los siglos XIV y XV fueron importantes en cuanto a reformas sobre el recinto amurallado, destacamos el siglo

\footnotetext{
${ }^{8}$ O común, aquel cuyos cajones se superponen sin ningún elemento vertical que los articule (Graciani y Tabales, 2003, 1)

9 Los análisis químicos de estos tapiales arrojaron un alto contenido de cuarzo y silicatos $\left(\mathrm{SiO}_{2}\right)$ y $\mathrm{CaO}$ y pérdida por calcinación (PC) asignables al $\mathrm{CaCO}_{3}$ (carbonatos). Respecto al contenido de $\mathrm{SO}_{3}$, ha sido muy bajo para los cuatro tapiales oscilando entre $0,01 \%$ y $0,05 \%$, teniendo por lo tanto escasa relevancia e indicando que no se utilizó yeso (sulfato de calcio dihidrato, $\mathrm{CaSO}_{4} \cdot 2 \mathrm{H}_{2} \mathrm{O}$ ) para la confección de los mismos. De todos los tapiales estudiados para el recinto de la alcazaba y recinto secundario del Parque, se han encontrado similitudes en su composición mineralógica, solo se ha diferenciado ligeramente de los demás el tapial de la muralla de la alcazaba por presentar trazas de sal (halita) y trazas de dellaita (un silicato); además, es el que mejor valor de resistencia presenta (Alejandre y Martín del Río, 2008).
} 


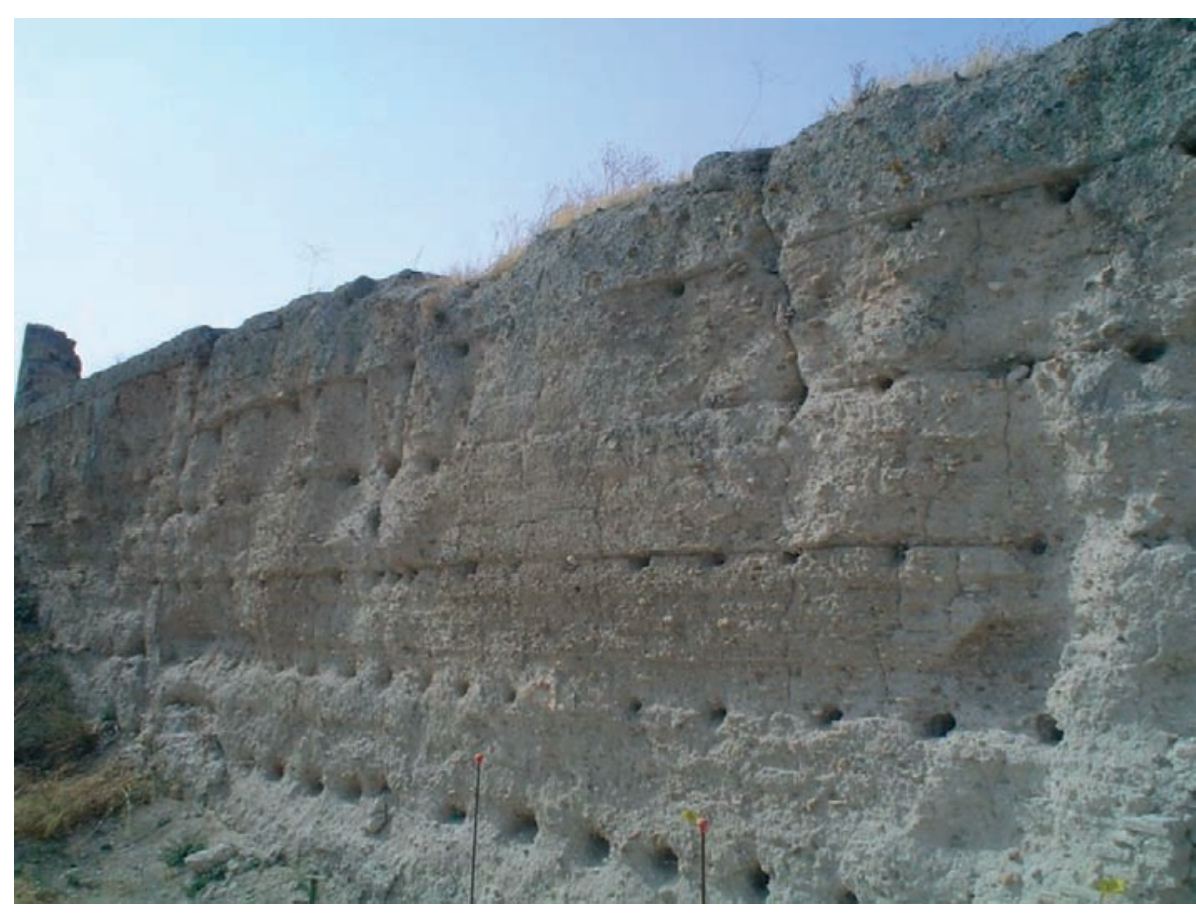

Fig. 4. Lienzo de muralla del recinto de la Alcazaba

XVI, fecha que delata una ocupación en la liza (SALAZAR DE MendozA, 1620, 75, 76, 108). Estos momentos vienen repletos de reformas, principalmente aquellas efectuadas con motivo de la boda en 1544 del duque de Marchena, don Luis Cristóbal Ponce de León, el cual desplegó un programa restaurador centrado, fundamentalmente, en todo este sector nororiental.

El principal objetivo, tras las labores arqueológicas, fue el de la conservación y consolidación de la muralla, que en aquellos momentos ya presentaba una imagen muy degradada, con fracturas que amenazaban un desplome de estructuras o una pérdida inminente de masa constructiva. Muestra de ello son los refuerzos de piedras y ladrillos que aparecen a lo largo del lienzo oeste.

Junto a eso, han emergido unos potentes contrafuertes de mampuesto de unos 12'50 m de longitud (U.E. 218, U.E. 221) que apoyan sobre una fina capa de cal, documentada como el suelo utilizado en el siglo XVI. Primero se construyó el contrafuerte que está más al norte, pero ante el peligro de derrumbe de la zona adyacente se construyó el otro. Ambos venían acompañados de unos refuerzos de ladrillos que tapaban desmejoras en el tapial (U.E. 212, U.E. 224, U.E. 206) y todo el conjunto estaría recubierto de un enlucido del que se conservan exiguos testigos (U.E. 213, U.E. 225).

Uno de los aspectos más destacables son los restos perdurables de la recubrición (capa de enlucido) que se hizo de la muralla, posiblemente del siglo XVI (U.E. 234,
U.E. 227, U.E. 228). El color es blanquecino, aunque su estado de conservación permite suponer una rápida desintegración si los trabajos de restauración no se aceleran.

En definitiva, esta cara oeste experimentó no sólo unas mejoras constructivas, sino también estéticas, a las que se le unió la idea del ajardinamiento para servir como vergel al antiguo palacio ducal el cual se ubicaba en la explanada del cerro de la Mota (RAVÉ, 1993, 121).

\section{PROCESO 10. Segunda mitad del siglo XX. Añadidos contemporáneos}

En los últimos años del siglo Xx, la muralla experimentó un rápido deterioro entrando en fase de ruina. Su estado de abandono y la falta de funcionalidad del lugar durante siglos potenció la degradación de la estructura, por lo que se podría decir que este sector nororiental de la muralla era más una ruina convertida en muladar, que un emblemático y significativo monumento de la historia de Marchena.

En algunas zonas se produjo un acoplamiento en los muros de una serie de casetas para usos desconocidos. Parte de los mechinales originales de la fábrica almohade fueron reutilizados para nuevas viguetas, de ahí que sean mucho más gruesos que los primitivos y que esa zona presente los negativos de haber sostenido algún forjado (U.E. 231, U.E. 255). Se sabe que una de esas construcciones sufrió un incendio, al apreciarse una interfaz de ceniza, y que por alguna causa desconocida, aunque todo apunta a la falta de 


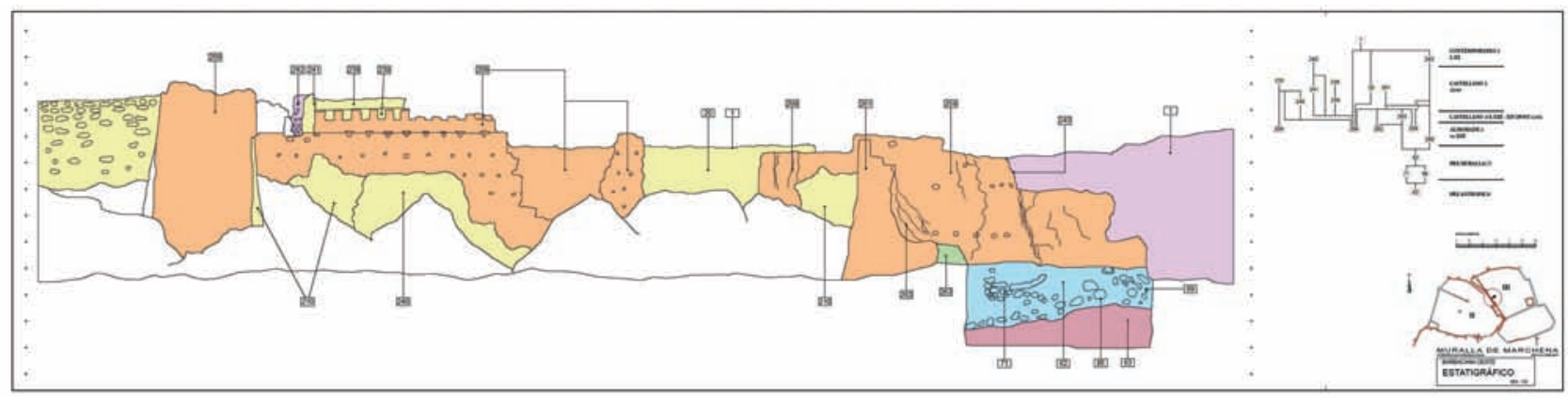

Fig. 5. Análisis estratigráfico de la barbacana del recinto de la Alcazaba

mantenimiento, se produjo una ruptura del tapial y su desplome.

Por último, durante una serie de años se fue colmatando parte de esta zona con rellenos de tierra contemporáneos (U.E. 1) que presentaban todo tipo de materiales, muy especialmente fragmentos cerámicos que abarcaban un amplio período histórico, desde época romana altoimperial hasta finales del siglo XX.

\section{Barbacana del recinto de la Alcazaba (sector nororiental) (Fig. 5)}

\section{PROCESO 1. Pre-almohade (I). Terreno natural}

Las excavaciones que efectuamos por todo ese sector arrojaron algunos datos relevantes. El registro arqueológico se agotó a una cota de $125^{\prime} 45$ m.s.n.m., en la cual apareció un nivel de tierra compacto de color blanquecino con unas ondulaciones laminadas (U.E. 63) por toda su superficie.

Era un terreno puro, en el que no se observaron restos materiales de ningún tipo, tan sólo los relativos al nivel superior (U.E. 62). Se trataba de un estrato natural que aportaría una escasa información a las investigaciones en curso.

Por consiguiente, se puede deducir que los árabes, posiblemente, no conocieron cotas tan bajas, sino que para la construcción de los recintos amurallados, partieron de estratos superiores sobre los que adecentaron el firme para posteriormente construir sobre él.

\section{PROCESO 2. Pre-almohade (II). Derrumbes de mampostería}

Por encima del estrato natural se extrajo un extenso paquete de tierra (U.E. 62) de color amarillento, con una matriz arcillosa, de textura suelta, suave y muy fina y una consistencia débil. Está compuesto por piedras, mampuestos, restos óseos humanos y animales y material lítico prehistórico. Es la tierra característica de Marchena y de la que se extrae la piedra calcarenita.
Se exhumó una gran cantidad de mampuestos volcados en orientación descendente que parecían revelar la presencia de alguna estructura previa a la muralla, pero de la que no se tiene más constancia, ni de su fisonomía ni del momento en el que fue construida, más que la existencia de este derrumbe. Aunque todo apunta a que se trata de una construcción muy antigua, posiblemente prehistórica por los elementos materiales exhumados ${ }^{10}$.

Concluyendo, todo este relleno sirvió como base sobre la cual comenzar con el proceso de construcción del cerco defensivo.

\section{PROCESO 3. Primer período tardoalmohade. Construcción de la barbacana}

Nuestras investigaciones han arrojado una cronología tardoalmohade, del primer cuarto del siglo XIII ${ }^{11}$, corroborando así la datación propuesta en otras excavaciones efectuadas en el recinto amurallado. De estas últimas se deduce que la cerca de la Madina no poseía antemuro, a diferencia del perímetro de la ciudadela, que sí lo tenía (U.E. 208). Éste se construye de forma paralela a la cimentación de la muralla y presentaba una forma en talud al realizarse, principalmente, como refuerzo de la misma y apoyándose sobre la pendiente inclinada del cerro de la Mota.

No se planteó hacer una barbacana de principio a fin, puesto que su fisonomía no era la propia, sino que la idea original para la que se concibió esta estructura fue la de ser-

${ }^{10}$ Se han hallado rollos de arenisca, cuarcitas, lascas de sílex, sílex y un hacha calcolítica, mientras que en otros sondeos cercanos se hallaron gran cantidad de fragmentos cerámicos calcolíticos, hecho que apunta a fechar este tipo de relleno en un contexto prehistórico (Fournier, 2008).

${ }^{11}$ En base al estudio del material cerámico exhumado, nos encontramos con una cronología perteneciente al primer cuarto del siglo XIII. Han aparecido galbos, bordes y bases con repie anular desarrollado de ataifores carenados con cubiertas vítreas transparentes y meladas oscuras y pastas rojizas; ataifores de la serie bícroma mixta (decorados en verde exterior y melado interior, de pastas rosadas, en verde interior y verde claro muy diluido exterior, de pastas pajizas); galbos del solero de candiles de cazoleta y pie alto, de pastas rojizas y cubierta plúmbea transparente; galbos y bordes de lebrillos espatulados; galbos de cazuela de costillas; carenas de orzas con cobertura vítrea total y pastas rojizas; galbo de jarrita de servicio de paredes finas bizcochadas con goterón de vedrío verde, etc. (Fournier, 2008). 
Fig. 6. Remate almenado de la barbacana. A la izquierda recrecimiento posterior del almenado

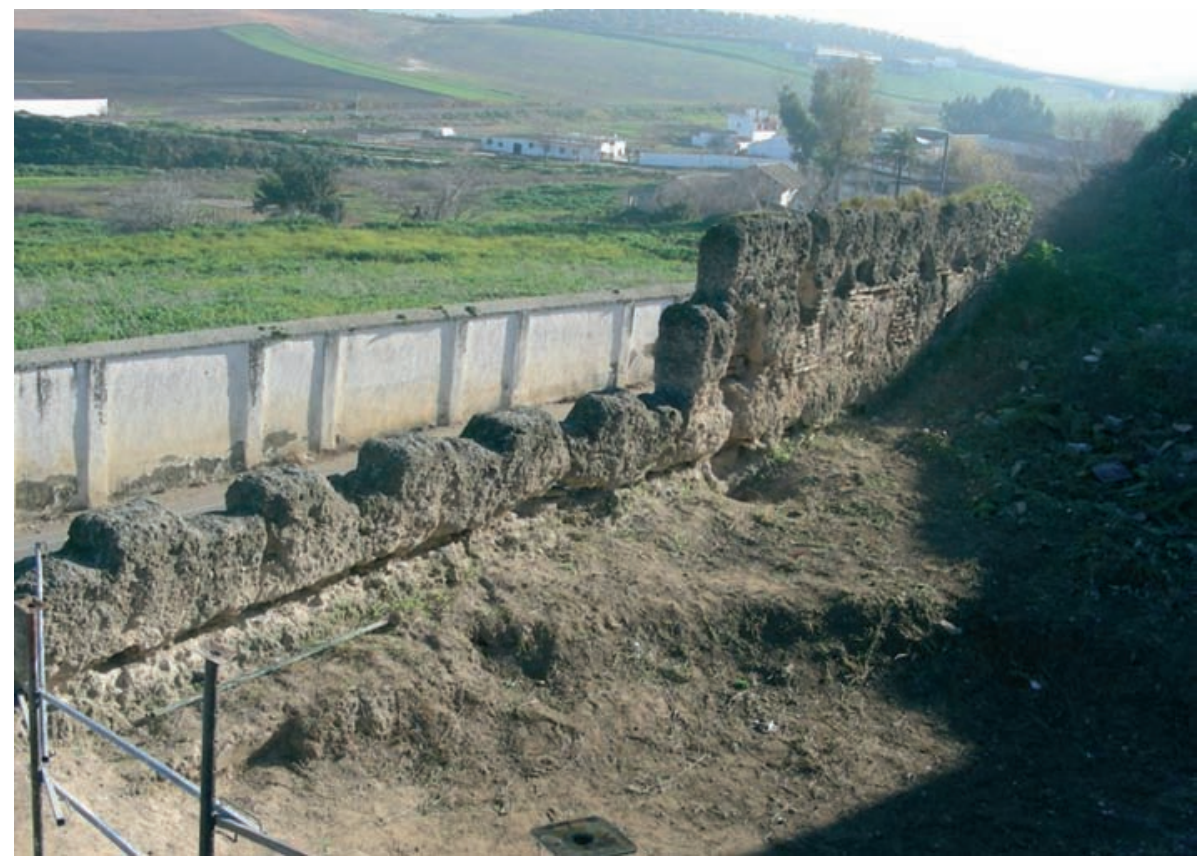

vir como potente contrafuerte al sistema de cimentación de la muralla. No obstante, adoptó el uso propio de un antemuro y se remató con un frente almenado y la creación de un estrecho adarve.

Sus dimensiones son inferiores a las del cerco defensivo $^{12}$, pero ambos utilizan la misma técnica constructiva a base de cajones de tapial simple (Graciani y TABALES, 2003, 1), de un módulo oscilante entre 0’88 - 0’90 $\mathrm{m}^{13}$.

\section{Proceso 5. Fase inicial castellana. Reformas en el siglo XV} En esta fase se documenta un revestimiento de mampostería (U.E. 263) sobre una de las torres de tapial de la barbacana (U.E. 262) ${ }^{14}$, que se encuentra muy fragmentada. Tenemos constancia de que, en general, fueron abundantes las transformaciones efectuadas por los primeros cristianos en otros tramos amurallados, las cuales se caracterizaron, básicamente, por el uso de la mampostería.

No obstante, es muy posible que realizaran alguna reparación más en esta cara oeste, aunque no se conserva en la actualidad debido a las posteriores reformas que transformaron el aspecto de gran parte del sector.

\footnotetext{
${ }^{12} \mathrm{La}$ muralla del recinto de la Alcazaba, que se encuentra parcialmente destruida, presenta en la actualidad una altura máxima de 8'30 m desde el nivel de liza tardoalmohade (a una cota de 133'48 m.s.n.m.), siendo en origen mucho más elevada. El antemuro, que se encuentra fragmentado, presenta una altura de 1'80 m desde la liza tardoalmohade.

${ }^{13}$ Los estudios de granulometría efectuados en los tapiales demostraron que tanto el tapial de la muralla de la alcazaba como su barbacana presentaban una gran similitud, por lo que se utilizó el mismo tipo de tierra para su elaboración (Alejandre y Martín del Río, 2008).

${ }^{14}$ Dicha torre es la que aparece como elemento de conexión entre el recinto de la Alcazaba y el recinto del Parque.
}

\section{PROCESO 6. Segunda fase castellana. Reformas en el siglo XVI}

Como producto de las nupcias de don Luis Cristóbal Ponce de León, se acondicionó todo el sector del Portillo como jardín para el palacio ducal y se hizo una serie de reformas y reparaciones que afectaron igualmente al antemuro (RAVÉ, 1993, 120-121). En este caso se optó por un revestimiento de sillarejo aparejado (U.E. 210) que cubría todo el antemuro (U.E. 208) y sus correspondientes torres. Se tienen datos exactos de los trabajadores y de las fechas exactas en las que se hizo tal forro ${ }^{15}$.

Otra de las reformas efectuadas en este siglo fue el cegamiento del antiguo almenado almohade y la subida en altura del mismo (UU.EE. 238, 239), con un tapial similar al original, pero de clara factura posterior (Fig. 6) ${ }^{16}$.

En definitiva, en el siglo XVI se producen una serie de reformas definitivas que modifican por completo el antiguo aspecto del antemuro, pasando de ser una obra medieval hecha en tapial a tener una envoltura pétrea, más reforzada y ofreciendo una imagen más castellana.

\footnotetext{
15 Luis Sánchez, maestro local, reparó los muros en la zona de la barbacana. Los maestros Benito Muñoz y Juan Lucas trabajan en la renovación de las puertas del Castillo: Tiro, Postigo y Barbacana. En 1544 se acomete el empedrado que reviste el tapial de la zona de la barbacana (Ravé, 1993, 119, 120).

${ }_{16}$ Para la muestra de tapial de las almenas, se ha determinado una curva granulométrica de mayor finura que las demás (sin apenas fracciones gruesas) y con un gran contenido de finos menores de 63 micras $(23,6 \%)$. Esta mayor finura implicaba una mayor demanda de agua de amasado del mortero/ hormigón del tapial, que al evaporarse ha generado una mayor porosidad, dato comprobado experimentalmente (Alejandre y Martín del Río, 2008).
} 


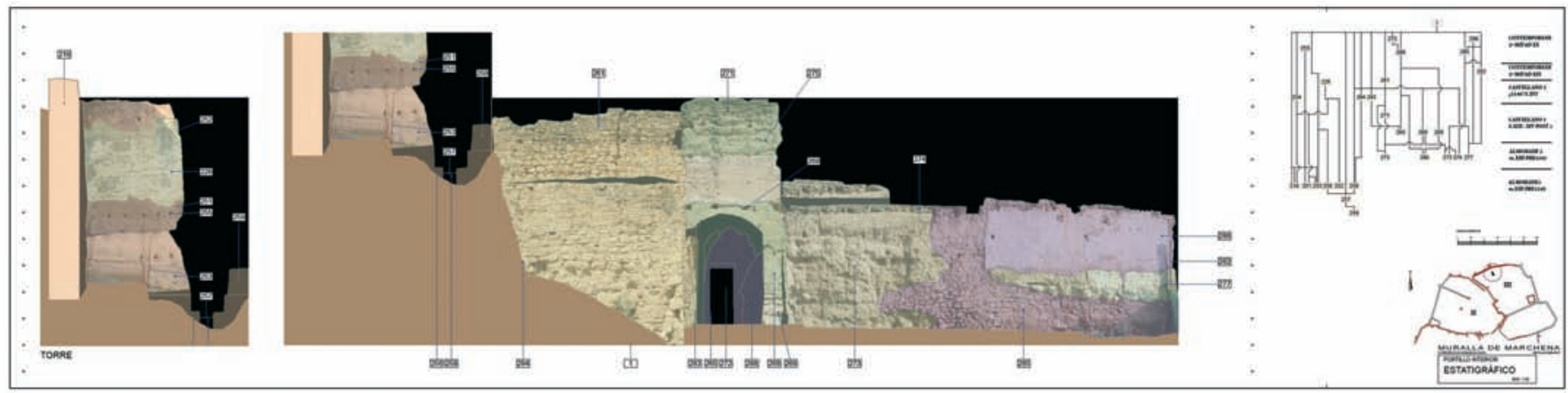

Fig. 7. Análisis estratigráfico del sector interior del Portillo (recinto secundario del Parque)

\section{Procesos 9 y 10. Siglo Xx. Añadidos contemporáneos}

El siglo XX ha sido el más destructivo para todo este sector, debido principalmente al abandono funcional del lugar, así como a la mala utilización de otras partes que quedaron destinadas al uso marginal, contribuyendo aún más a la desmejora.

Tras el paso de los años se fueron colmatando algunos espacios como la liza ${ }^{17}$ y ocultando con escombros algunas de sus estructuras.

Algunas construcciones del tipo casetillas se adosaron a los lienzos primigenios, deformando un tanto su imagen. Igualmente se procedió a cegar (U.E. 242) zonas más antiguas, como parece ser una antigua ventana (U.E. 241), en un intento por conservar esa estructura de un más que probable desplome.

En definitiva, los cambios efectuados sobre el conjunto en este período fueron negativos ya que distorsionaron su primitiva imagen y contribuyeron al aceleramiento de su deterioro.

\section{Sector interior y exterior del portillo (recinto secundario del parque) (Fig. 7 y 8 )}

\section{PROCESO 3. Primer período tardoalmohade}

En función de los tipos de fragmentos cerámicos hallados y de la técnica constructiva empleada, se ha podido encuadrar la cronología de la muralla en los primeros años del siglo XIII, confirmando así la datación planteada en anteriores excavaciones efectuadas en otros tramos de la cerca.

Se presupone que esta construcción tuvo un breve período de uso por parte de los almohades, ya que Marchena fue conquistada en 1241, transcurriendo escasos

\footnotetext{
17 Este inmenso relleno contemporáneo estaba conformado por todo tipo de fragmentos cerámicos, ofreciendo una secuencia abarcable desde el período altoimperial romano hasta época contemporánea.
}

años entre su terminación y la reutilización por el nuevo poder cristiano.

La técnica constructiva adoptada es el tapial común o simple, tan característico en murallas de la misma época ${ }^{18}$. Se trata de una tapia mejorada con añadidos como la cal y los áridos. Se presenta mediante cajones continuos (UU.EE. 251, 253) en una superposición directa y de un módulo alto ${ }^{19}$ oscilante entre los de 0'88-0'90 m, unidos con hiladas de cal y dejando a la vista los mechinales ${ }^{20}$, muchos de los cuales conservan las agujas de madera originales ${ }^{21}$.

Para la construcción de este recinto, se eligió un lugar privilegiado ubicado en un promontorio al extremo de la ciudad, para facilitar la evacuación en caso de peligro, ofrecer una mejor defensa y exaltar su carácter simbólico (Izquierdo, 1996, 104). En primer lugar, prepararon el terreno, para lo que procedieron a su colmatación mediante capas de tierra y $\mathrm{cal}^{22}$. Paralelamente, se fue levantando el antemuro con una forma en talud (UU.EE. 259, 260), debido a que su principal función era la de servir de refuerzo a la muralla, y edificando la muralla, mediante una base de cimentación consistente en una doble zapata (UU.EE. 14, 229).

\footnotetext{
18 Graciani y Tabales $(2003,1)$ plantean tres tipos de tapial según su composición: tapial común o simple, encadenado y de fábrica mixta

19 Según las dimensiones del tapial, Graciani y Tabales $(2003,2)$ han distinguido entre: módulo alto, aquel que oscila entre 0’85 y 0’95 m, y módulo bajo, de altura inferior o igual a 0’80 m.

${ }^{20}$ Donde se combinaron dos tipos de agujas: planas y de rollizo (Graciani, 2008). ${ }^{21}$ Aparentemente, predominan las agujas de rollizo, aunque esta forma pudo deberse a la pérdida de masa provocada por anidamientos o incluso por la incorporación de viguetas de forjados de construcciones adosadas a la muralla en la segunda mitad del siglo xx; UU.EE. 231 y 235 (Graciani, 2008).

22 En estas capas aparecieron materiales cerámicos muy diversos (Fournier, 2008), desde piezas campaniformes (galbos de vasos o cuencos con decoración geométrica, ...), pasando por la edad del hierro, época turdetana, romana, período emiral-califal, califal-taifa, y muy especialmente tardoalmohade (galbos de paredes acanaladas de cántaros, galbos de ollas, fragmentos de cazuelas de costilla y de pico vertedor, carenas o bordes de ataifores, jofainas, etc.).
} 

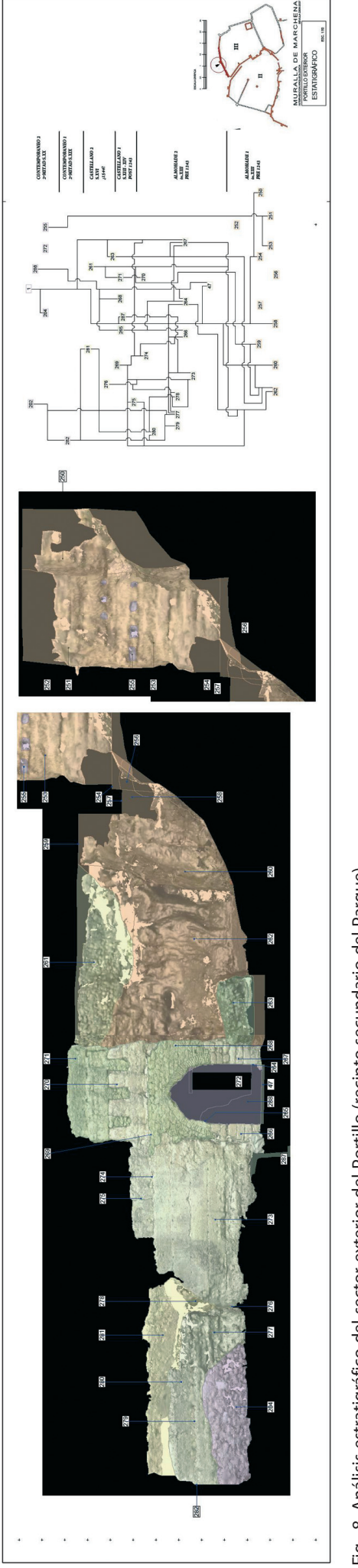

Aunque las medidas originales serían más elevadas, la altura superior que se conserva del lienzo murario (U.E. 216) es de unos 8'30 m desde el nivel originario almohade de la liza (a una cota de $133^{\prime} 48$ m.s.n.m.). Sin embargo, desde el suelo actual la altura del antemuro es de 7’30 m.

Se mantienen en pie una serie de torres primigenias que rodeaban el perímetro amurallado. En estos alzados se conserva una de ellas, con una altura de $7^{\prime} 80 \mathrm{~m}$. Enfrente se encuentra el antemuro, al cual se adosan, aunque muy fragmentados, restos de un antiguo torreón cuadrangular de tapial (U.E. 262) 23 , del que se aprecian escasos $7 \mathrm{~m}$ desde la superficie actual, con restos del calicastrado (U.E. 64) que se utilizaron para su fábrica, así como de un debilitado revestimiento de mampostería (U.E. 263).

Dichas torres presentaban en la zona superior una decoración en bandas de ladrillos, rasgo característico del momento, apreciable también en otras cercas como la de Sevilla, Badajoz, Cáceres o Jerez (AzUAR, 2004, 69).

Es, por tanto, en este primer proceso datado cronológicamente en el primer cuarto del siglo XIII, cuando se acomete la construcción del recinto de la Alcazaba (muralla y antemuro) y del recinto amurallado que albergaba a la antigua ciudad.

\section{PROCESO 4. Segundo período tardoalmohade. Ampliación}

Tras el crecimiento de necesidades, se planteó la construcción de un espacio secundario fortificado acoplado al conjunto amurallado de la Alcazaba. Éste funcionaría, probablemente, como uso exclusivo y de disfrute de los altos cargos y presentaría un aspecto ajardinado, aunque no debe descartarse una función de albacar o cualquier otra que se nos escape. Se encontraba igualmente amurallado y rodeado de torres adosadas a los lienzos.

La entrada al mismo se realizaba por un acceso conocido como el Portillo. En su día pudo tratarse de un arco de herradura del que nada se conserva a excepción de sus cimientos (UU.EE. 37, 48) ${ }^{24}$, el arranque del mismo realizado con ladrillos y unas jambas de sillares de piedra calcarenita (UU.EE. 266, 267), propia de las canteras existentes en la localidad. Aún se conservan el antepecho y

${ }^{23}$ Este torreón es el que servirá como nexo de unión entre el recinto del Parque y el conjunto de muralla y antemuro.

${ }^{24}$ Uno de los torreones de la barbacana tenía adosado por su flanco este el conocido acceso en arco del Portillo. Tras las excavaciones llevadas a cabo, se cree en la existencia de una puerta anterior del período tardoalmohade, o cristiano (muy inicial), y del reaprovechamiento de sus cimientos para el nuevo acceso medieval. 
Fig. 9. Lienzo de tapial de la cara interna del recinto del Parque. A la izquierda, el Portillo desde el interior

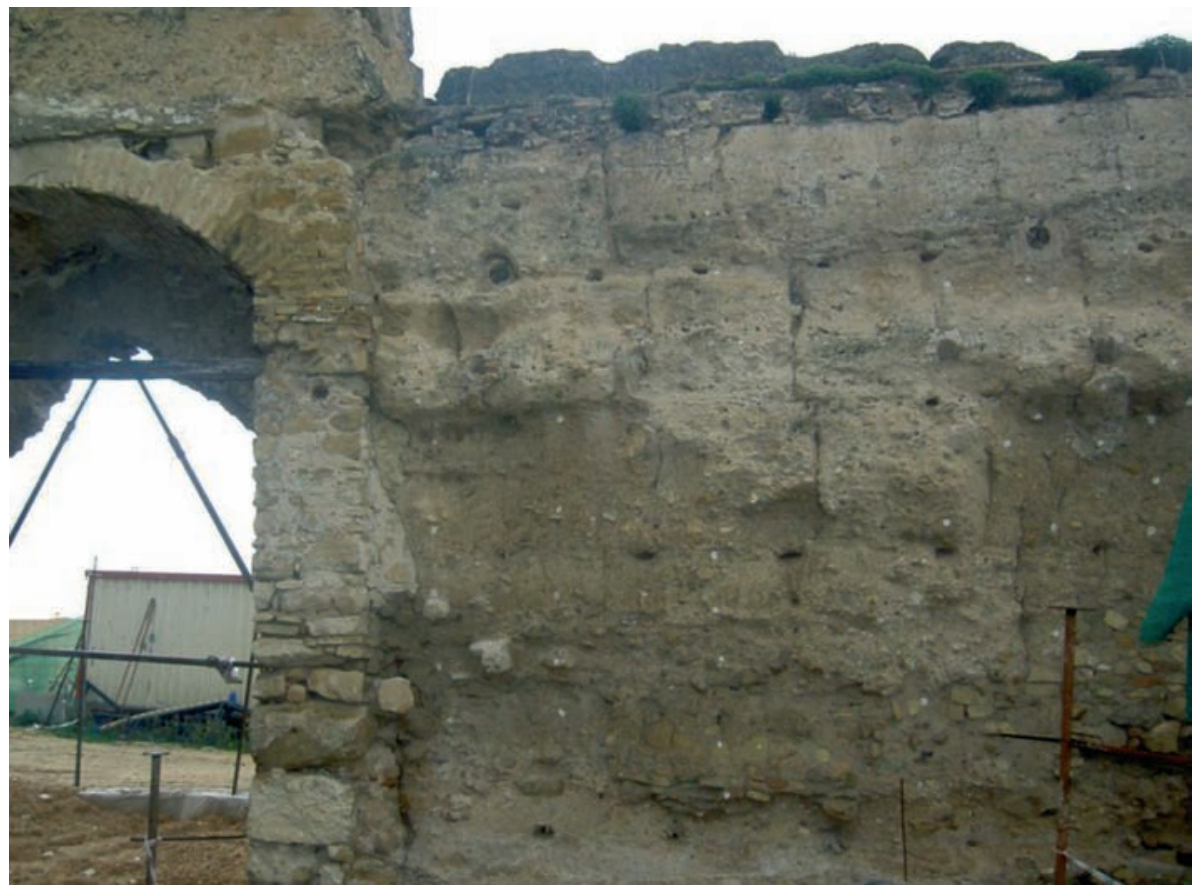

el almenado original (U.E. 270), así como una verdugada de menudos mampuestos alternados con ladrillos (U.E. 274) que separan el lienzo murario (U.E. 273) del remate superior, el cual recorrería todo el recinto.

La fábrica utilizada era igualmente a base de cajones de tapial simple, con unas características similares a las de la muralla y antemuro. Sin embargo, los cajones tienen unas medidas que oscilan entre 0’70-0’71 $\mathrm{m}$, por tanto son de módulo bajo (Graciani y Tabales, 2003, 2). Es también una tapia mejorada que utiliza cal como conglomerante, aunque en menor cantidad que el caso anterior, y áridos cerámicos. En esta fábrica se observan diferencias dependiendo de la zona, ya que en el lienzo (U.E. 273) contiguo al Portillo no se aprecian juntas verticales (Fig. 9), sin embargo, al otro lado de la carretera (donde continua el recinto del Parque), los tramos encofrados son menores y están separados

Fig. 10. Juntas oblicuas en los cajones de tapial del lienzo situado al otro lado de la carretera (recinto del

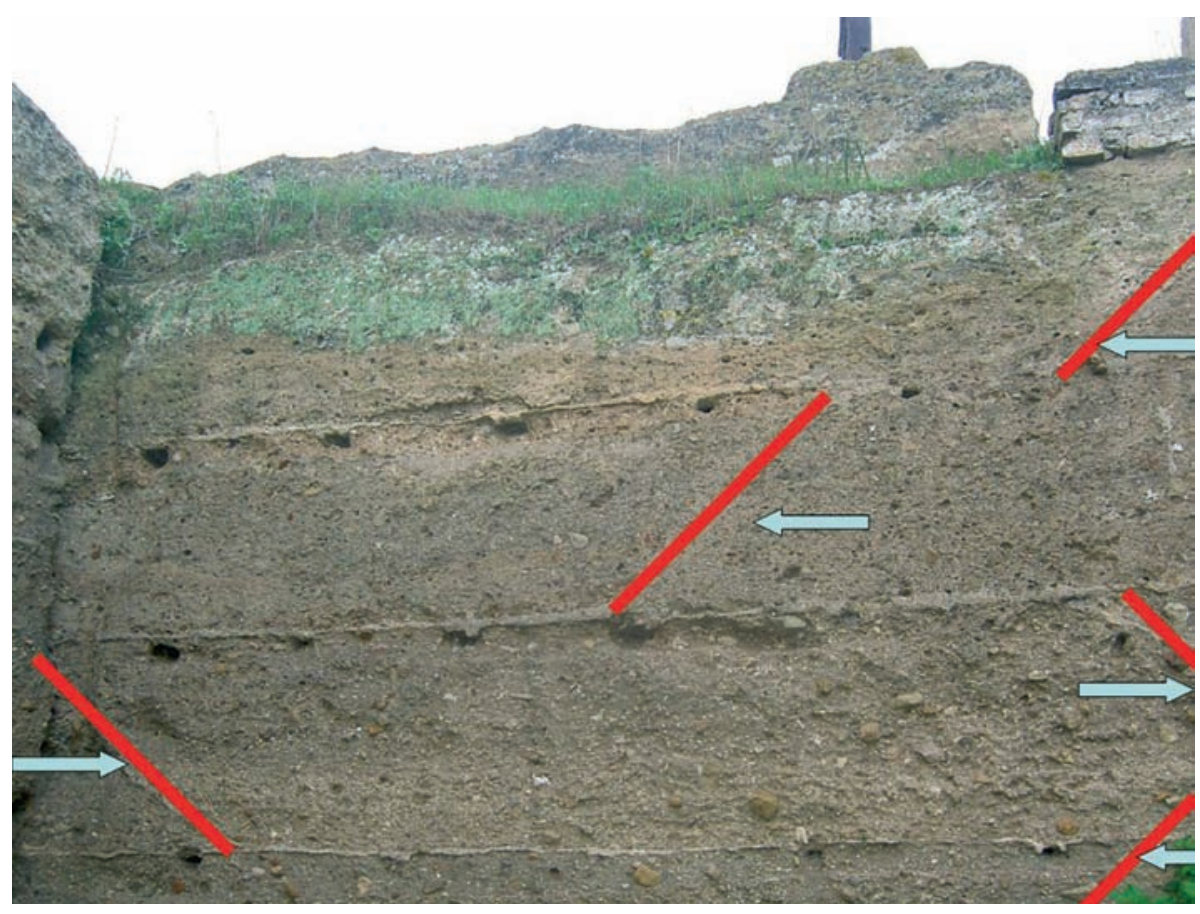


por un curioso sistema de juntas verticales ${ }^{25}$ (GRACIANI, 2008) (Fig. 10). En definitiva, es una obra menos costeada que la anterior (muralla-barbacana) y realizada de una forma más rápida. Es por ello, que planteamos su cronología en un momento posterior a la construcción de la muralla, pero dentro del período tardoalmohade en una fase muy final, o bien, en una etapa cristiana inicial.

El estado de conservación en general es pésimo, debido a que una parte del lienzo murario fue destruido en la segunda mitad del siglo XIX como consecuencia de la construcción de la carretera comarcal que lleva a Carmona. Además es una zona abandonada desde hace años, que tuvo durante un largo período construcciones marginales adosadas a sus muros, presentando, por ende, continuos parches y arreglos de escasa calidad.

\section{PROCESO 5. Fase inicial castellana. Reformas en los siglos $X I V-X V$}

Según la tradición local, la conquista cristiana de Marchena comenzó por el aludido Portillo. Tras las correspondientes analíticas murarias, se han podido determinar con exactitud una serie de transformaciones efectuadas tras la toma de la villa por el reino cristiano, las cuales generaron un amplio programa de reformas a lo largo de todo el perímetro amurallado. Su rasgo distintivo se basó en el uso de la piedra para la refacción y el refuerzo de ciertos lienzos y torres.

En relación al acceso, se eliminó el probable arco de herradura, reutilizando su zócalo de sillares para levantar otro apuntado y de ladrillos (U.E. 265) con una luz de unos 2'30 $\mathrm{m}$. No existe una ruptura estructural con el primitivo muro de tapial en el que se inserta el arco, salvo en lo imprescindible. Es decir, mediante una sutil obra reaprovechan el primitivo lienzo eliminando la rosca del arco (posiblemente de herradura) para realizar otro, con un nuevo enmarque de mampostería (UU.EE. 269, 268) (Fig. 11).

Para defender el nuevo Portillo, incorporaron al Este un potente bastión castellano de mampostería aparejada (U.E. 287), con forma semicilíndrica, que hemos documentado en sus cimientos tras las excavaciones ${ }^{26}$. Éste presentaría un aspecto similar al de otros torreones que circundan la muralla de la medina. Tal es el caso de los ubicados entre el conocido Arco de la Rosa o puerta de Sevilla hasta el ayuntamiento de la localidad.

\footnotetext{
25 Rasgo propio y apreciable también en el Castillo de San Romualdo (San Fernando, Cádiz).

${ }^{26}$ La cota más alta de los escasos vestigios conservados es 127 ’39 m.s.n.m. y la cota más baja 126'84 m.s.n.m. Su zapata se encuentra a 124 ’94 m.s.n.m. y la base de cimentación está a 124 ’21 m.s.n.m.
}

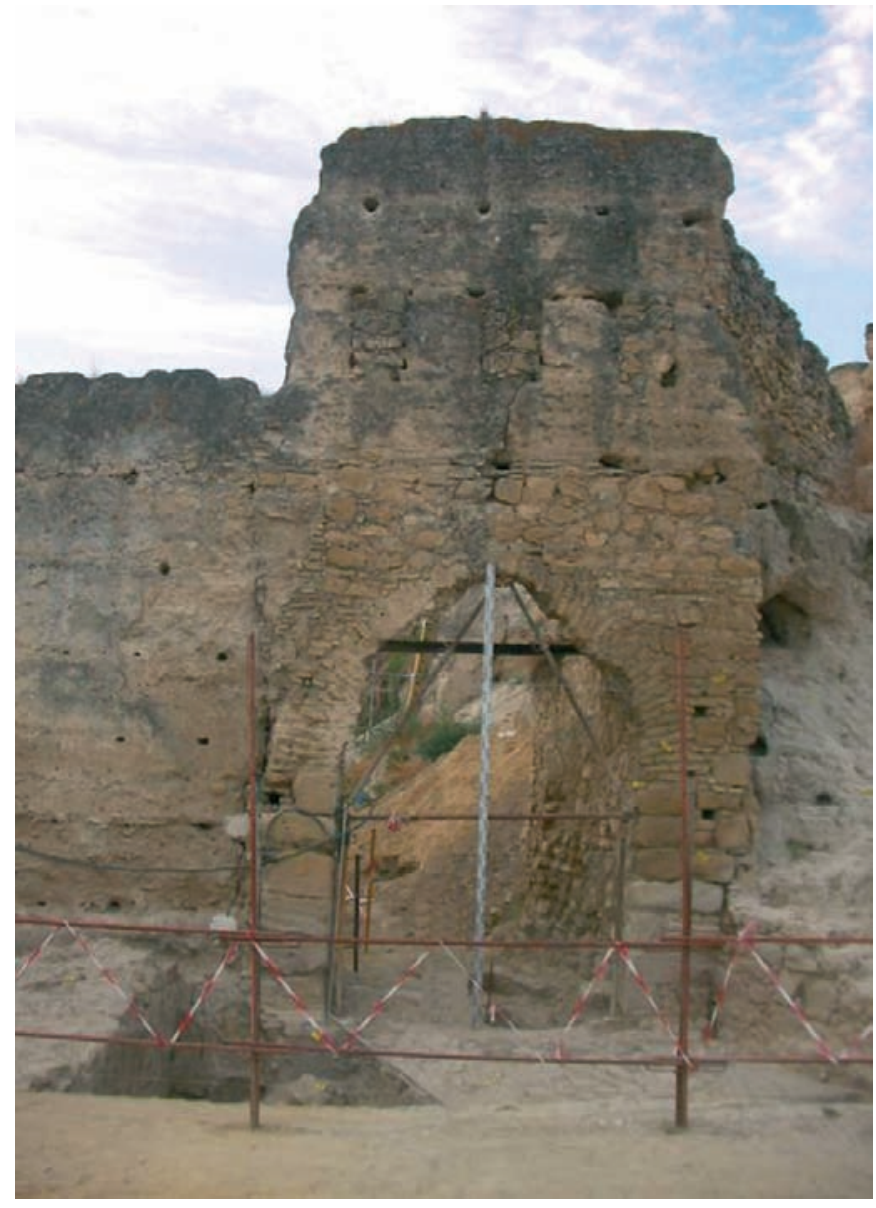

Fig. 11. El Portillo. Imagen durante el transcurso de las excavaciones

\section{Proceso 6. Segunda fase castellana. Reformas en el siglo XVI}

A lo largo del siglo XVI se llevaron a cabo una serie de reformas que afectaron a todo el entorno del Portillo. Estas labores se deben a don Luis Cristóbal Ponce de León, el cual organizará una amplia actividad reparadora en todo este sector.

$\mathrm{Su}$ labor se centrará en el acondicionamiento del recinto, convirtiéndolo en jardín renacentista y perdiendo su anterior función como huerta. Actuará como vergel del palacio ducal que se ubicaba dentro del recinto de la Alcazaba, en la zona más elevada de la Mota.

Asimismo, se cegó el primitivo remate almenado con mampostería (U.E. 270) y se elevó la altura del paramento con dos nuevos cuerpos de cajones de tapial (U.E. 271), de los que tan sólo conservamos los correspondientes al Portillo ${ }^{27}$.

\footnotetext{
27 En estos tapiales se observan las mismas características que en los tapiales correspondientes a la ampliación almenada de la barbacana. Ambos se presentan, respecto al resto de tapiales estudiados en el entorno del recinto de la Alcazaba y
} 
En ambos alzados, se dejan ver unos arreglos y soportes a base de mampostería que apoyan en los lienzos almohades. Tal es el caso del gran lienzo de mampuestos (U.E. 261) que descansa sobre una torre de tapial de la barbacana (U.E. 262) y se refuerza con un pie de amigo en ángulo.

\section{PROCESO 8. Reformas en el siglo XIX}

En esta fase se aprecian radicales transformaciones que cambiaron por completo la fisonomía del recinto del Parque, ya que en la segunda mitad del siglo XIX se llevó a cabo la supresión de una parte del lienzo (U.E. 282).

La causa fue la construcción de la carretera comarcal C-339 que conduce a Carmona, para la cual se tuvo que eliminar un tramo considerable del recinto secundario.

\section{Proceso 10. Segunda mitad del siglo XX. Añadidos contemporáneos}

En este último período se produce la degradación más seria de la muralla. No sólo lleva todo el siglo casi abandonada, sino que además, determinados puntos del recinto sufrieron un uso inadecuado al adosarse sobre sus muros una serie de construcciones marginales destinadas a la cría de animales.

Asimismo, existían pequeñas casetas adosadas a la muralla con funciones desconocidas y que reutilizaban los antiguos lienzos como paredes de la misma. Es por ello, que se han encontrado grandes perforaciones en el tapial original, concretamente sobre los primitivos mechinales (U.E. 255), los cuales aumentaron de tamaño al incorporar las grandes viguetas que sostendrían la techumbre.

La falta de materia constructiva también fue rehecha en esta época mediante una amalgama de mampostería irregular, restos de sillares, fragmentos marmóreos, ladrillos, etc., que sirvieron como parche a zonas arruinadas y descompuestas.

Y por último, para evitar un inminente desplome del arco del Portillo, se tabicó el hueco con ladrillos y sobre él se abrió una nueva puerta para que se comunicaran los dos espacios que hay en ambos frentes del acceso.

del Parque, muy ricos en cal y con unos valores muy altos de porosidad. Además, para su elaboración se utilizó la tierra más fina con la curva granulométrica más alta, pudiéndose especular que se seleccionó para la ejecución de las almenas (elementos constructivos de carácter defensivo). No obstante, podemos decir que su calidad es baja respecto al tapial utilizado en la muralla del recinto de la Alcazaba (Alejandre y Martín del Río, 2008).

\section{Puerta de Sevilla (Fig. 12)}

PROCESO 5. Fase inicial castellana. Reformas en el siglo XV Tras la gran devastación sufrida en Marchena en 1368 por Muhammad V, aliado del rey de Castilla ${ }^{28}$, la muralla tardoalmohade se resintió considerablemente, necesitando una completa reedificación de sus muros en diversos sectores.

Tras unos años de estancamiento en cuanto a actividad constructiva, se produjo la gran reparación en la muralla, que quedó reflejada unos siglos después por Salazar de Mendoza en su Crónico de la excelentíssima casa de los Ponces de León (1620), así como en una inscripción que estuvo inserta en la Puerta de Sevilla durante siglos. Gracias a ello, sabemos que siendo don Pedro Ponce de León V Señor de Marchena, el papa Martín V otorgó una bula para la reedificación de los muros de esta villa y ofreció gentilezas a todos aquellos cristianos que contribuyeron a la realización de dichas labores, concluidas en 1430.

En este sentido, pensamos que el entorno de la Puerta de Sevilla (puerta, torres cuadrangulares y lienzo así como todas las torres semicirculares repartidas por el perímetro amurallado) pertenece a este mismo momento y no a otro anterior. Por ende, destacamos dos razones por las que creemos que esta gran reconstrucción se efectuó en el siglo XV: por un lado, la concesión de la bula para tal fin, hecho que nos lleva a la idea de que no sería una simple reforma al estilo gótico, propio de la época, sino una obra de mayor envergadura junto a una reorganización del trazado, máxime cuando es el papa el que la otorga; y por otro, la documentación conservada pone de manifiesto el período de guerras fronterizas que padece esta población hasta el último cuarto del siglo $\mathrm{XV}$, motivo más que suficiente para rehacer el ruinoso cerco defensivo (García, 1996, 77).

Esta importante reparación devolvió a Marchena su carácter fortificado y monumental, propio para dirigir desde el Castillo de la Mota, lugar en el que se alojaron los Reyes Católicos y don Rodrigo Ponce de León (I Marqués de Cádiz), gran parte de las operaciones militares contra el Reino de Granada en 1485 (GARCíA, 2005, 261).

En el caso de la Puerta de Sevilla, también conocida como Arco de la Rosa, presenta una fábrica prácticamente uniforme a base de mampuestos. Teniendo en cuenta que en el período anterior construían fundamentalmente con tapial, apuntamos su posterioridad constructiva con respecto al conjunto amurallado tardoalmohade.

\footnotetext{
${ }^{28}$ A consecuencia del apoyo incondicional del II y III Señor de Marchena, d.
} Pedro Ponce de León y su hijo d. Juan al conde de Trastámara. 

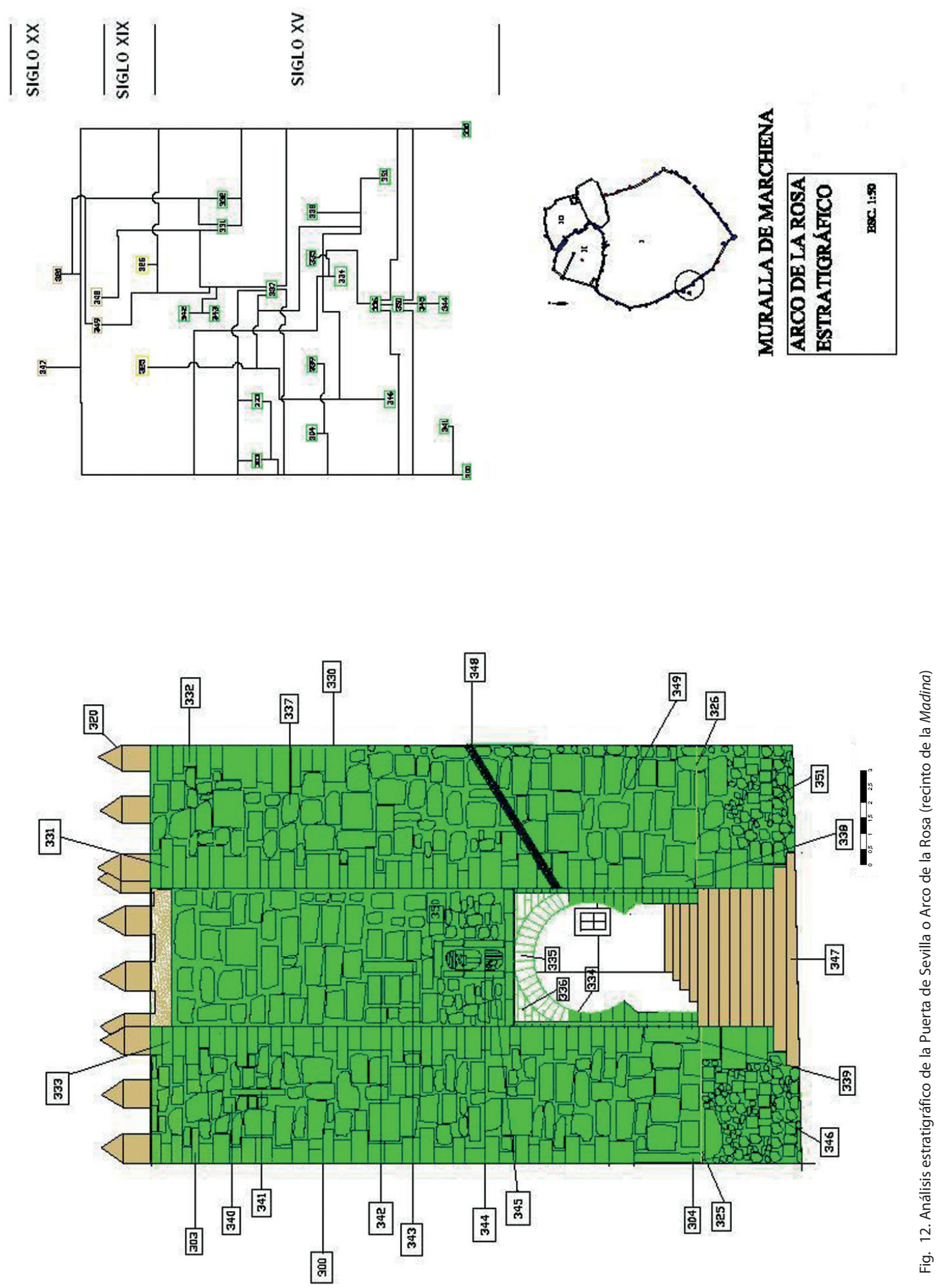
Fig. 13. Lienzo U.E. 323 con la zona superior de ladrillos y las incorporaciones de diversos vanos. (Puerta de Sevilla, recinto de la Madina)

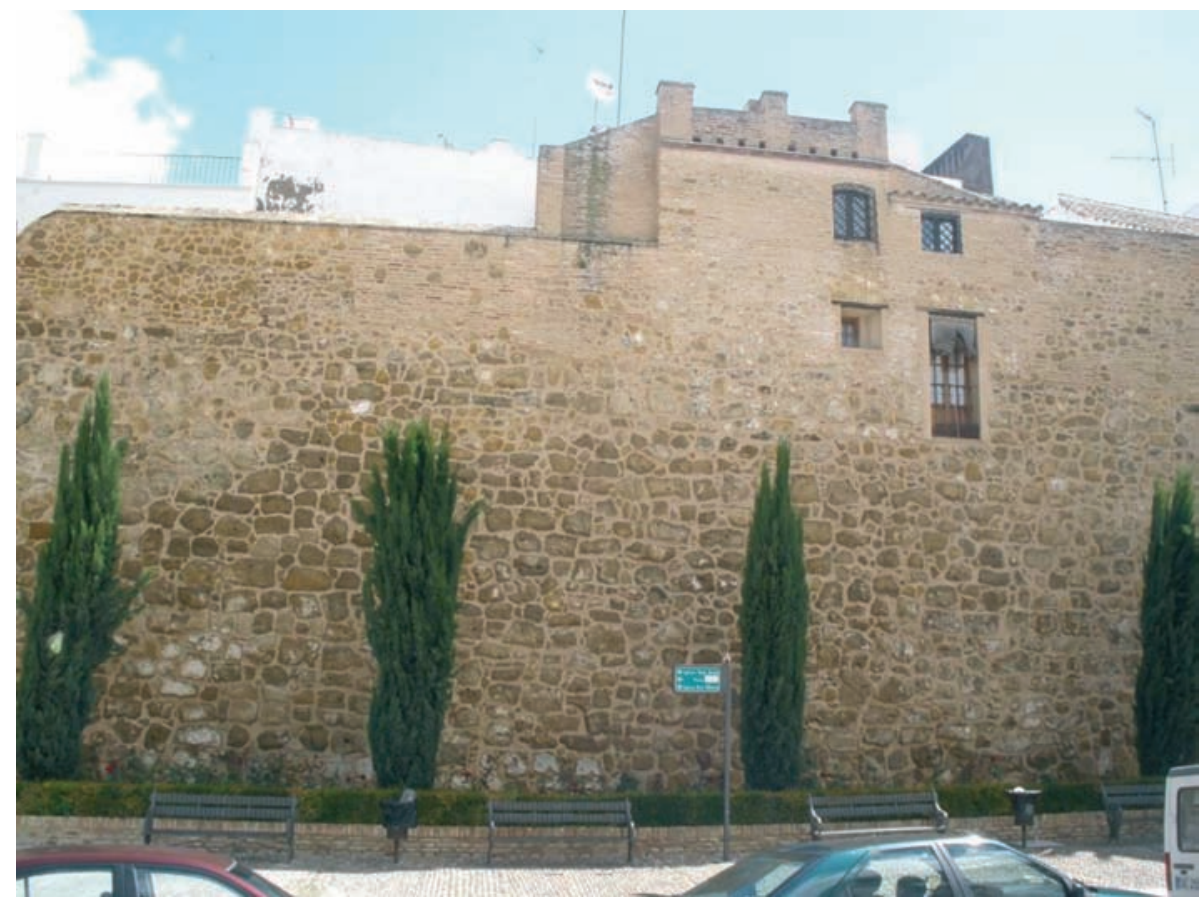

Lo cierto es que abrieron como puerta un arco de herradura (U.E. 334), sin apuntar, flaqueando por dos esbeltas torres ${ }^{29}$ que presentan cadenas de sillares en sus esquinas (UU.EE. 302, 303, 331, 332, 333) y bajo las mismas, a modo decorativo, fustes de columnas marmóreas de acarreo romano (UU.EE. 304, 338, 339). Igualmente, incorporaron una serie de elementos góticos tales como las marcas de canteros en las bóvedas, las gárgolas, las saeteras y los escudos de armas.

Con respecto a estos últimos elementos (UU.EE. 308, 344), ostentaban el emblema de los Colona, la familia del papa que ordenó las reformas, así como el de los Ponce de León, quienes favorecieron dichas obras.

Otra cuestión importante son las dovelas. Éstas conforman un arco de herradura sin apuntar, sin clave perfecta y cuya dovela principal no coincide con la clave o el centro del arco. Puede que fuera un arco de herradura apuntado y que tras alguna remodelación posterior alteraran la clave recolocando unas nuevas dovelas; o bien, es posible que en origen no fuera apuntado, sino tal y como se nos presenta hoy día, dejando de manifiesto que no nos encontramos ante una obra islámica, sino un arco realizado en un momento histórico posterior en el que no preocupaban en exceso las formas y proporciones, en contraposición al arco de herradura tardoalmohade que encontramos en la puerta de Morón.

29 Que en origen serían menos altas al ubicarse el nivel del suelo a una altura superior.
Una de las torres está unida a un lienzo de muralla que ha sufrido bastantes reformas en los últimos siglos, fundamentalmente en su zona superior; dicho lienzo enlaza, a su vez, con un torreón semicircular, también un poco alterado, pero provisto de la fábrica característica de este período constructivo.

Haciendo un riguroso análisis visual de los elementos constructivos, tanto la puerta (U.E. 334), como las torres cuadrangulares (UU.EE. 300, 330) y el torreón semicircular (U.E. 305), dejan entrever un aparejo de mampuesto careado de módulo medio-alto con tendencia a la horizontalidad. Sin embargo, el lienzo de muralla (U.E. 323), con un aparejo muy similar, se trata de mampuesto careado de módulo medio-alto y disposición irregular (Fig. 13). Por tanto, presentan una gran homogeneidad y parecen ser fruto de una misma fase constructiva ${ }^{30}$.

En cuanto a la planta de la muralla en el entorno de esta puerta, se puede observar cómo se ha forzado el quiebro en el trazado general. Es por ello que, tanto el conjunto de la puerta como las torres próximas, las atribuimos a la misma etapa constructiva (RAVÉ, 1993, 62).

Con respecto al zócalo que encontramos en las torres (UU.EE. 311, 346, 351), éste podría tratarse de la cimentación de las mismas, por lo que en origen la altura

${ }^{30}$ Los torreones semicirculares repartidos por todo el perímetro amurallado los relacionamos con este momento constructivo al observarse la misma técnica constructiva. 
correspondería a un nivel superior, justo por debajo de las columnas que aparecen empotradas en las esquinas. Ello justificaría la continuidad de la cadena de sillares hasta el final y el peor cuidado formal en la fábrica (mampuestos más irregulares).

En definitiva, muchas de las hipótesis que plantemos quedarían contrastadas mediante una excavación en todo este sector. A falta de ella, presentamos un primer análisis murario fundamentado en la documentación existente y apoyado por un riguroso estudio visual.

\section{PROCESO 8. Reformas en el siglo XIX}

Probablemente, ya en el siglo XIX, se bajó el nivel del suelo (U.E. 325) que se encontraba, en origen, en el arranque de las jambas del arco de herradura o por debajo de las columnas marmóreas ubicadas en las esquinas de las torres.

De igual manera, se realizaron una serie de parcheados de mampuestos repartidos por todo el conjunto, de los que destacamos uno de grandes dimensiones (U.E. 310) que constituye gran parte de la zona superior del lienzo (U.E. 323), exteriorizando, desde estos momentos, un remate diferente al que pudiera tener en origen, probablemente, más elevado y almenado.

Los parches de mampuestos de módulo pequeño e irregular aparecen distribuidos a lo largo de todo el lienzo y se extendían por la zona superior de la torre semicircular. Están relacionados con la edificación de balcones y ventanas, cuya incorporación quedó sellada con mampuestos y ladrillos.

Muy relacionado con los susodichos parcheados de mampuestos, encontramos una fábrica de ladrillos (U.E. 315 ), que se extiende por toda la mitad superior, sustituyendo lo que en origen sería un lienzo de mampuesto, pero que debido a la incorporación de vanos de las casas que tenía adosada la muralla por su parte trasera, se cambió su aspecto y se adaptó a los nuevos tiempos.

En una de las viviendas se optó por colocar un remate almenado con falsos mechinales que pretendía conseguir la concordancia con el aspecto medieval del conjunto.

\section{PROCESOS 9 y 10. Segunda mitad del siglo xx. Reformas contemporáneas}

A lo largo del siglo XX se llevaron a cabo numerosas reformas del entorno que cambiaron radicalmente su fisonomía.

Sabemos, a través de una serie de fotografías realizadas en los años 60, que se procedió a la construcción de un acceso escalonado de guijarros (U.E. 347) que sustituía a la

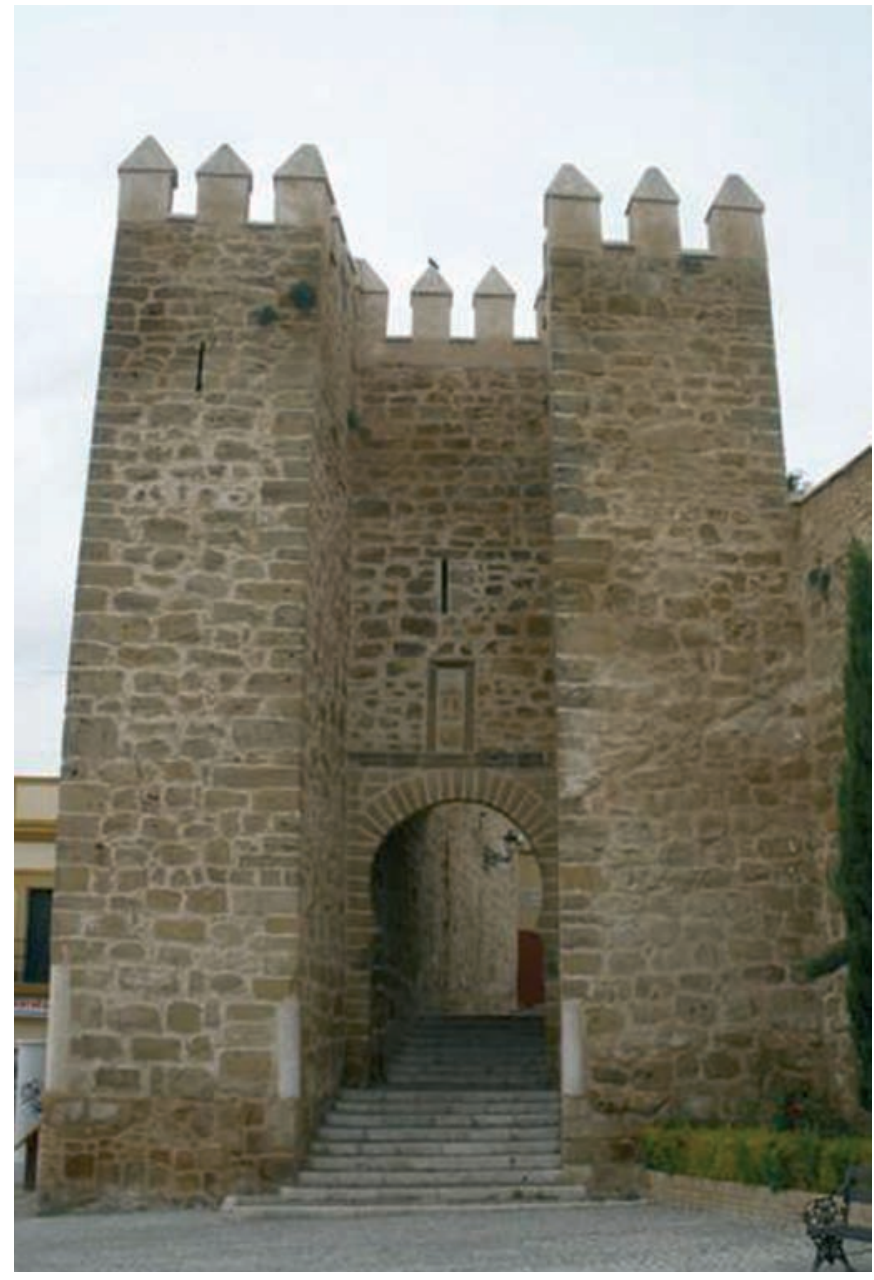

Fig. 14. Imagen actual de la Puerta de Sevilla

anterior rampa terriza que existía desde los orígenes de esta puerta.

Por estos años se procedió, igualmente, a una completa reparación del Arco de la Rosa, consistente en consolidar y rehabilitar su estructura, en rehacer el sistema almenado que se encontraba muy deteriorado y en algunas zonas casi desaparecido, y en demoler las casas anexas al lienzo de muralla, destinadas al comercio.

En torno a los años 70 del siglo XX se llevó a cabo la reconstrucción de gran parte del remate almenado. Algunos de sus merlones piramidales originarios aún se conservaban, tan sólo se rehicieron aquellos que habían desaparecido, y luego todos, tanto originales como nuevos, se recubrieron de un mortero blanquecino de cemento, distorsionando un tanto su primitivo aspecto medieval.

En definitiva, durante todos estos siglos, esta puerta ha sido una de las que más restauraciones han experimentado. En los últimos años ha sido sometida, nuevamente, a una limpieza y consolidación de la piedra y del llagueado (Fig. 14). 
Fig. 15. Análisis estratigráfico de la Puerta de Morón o
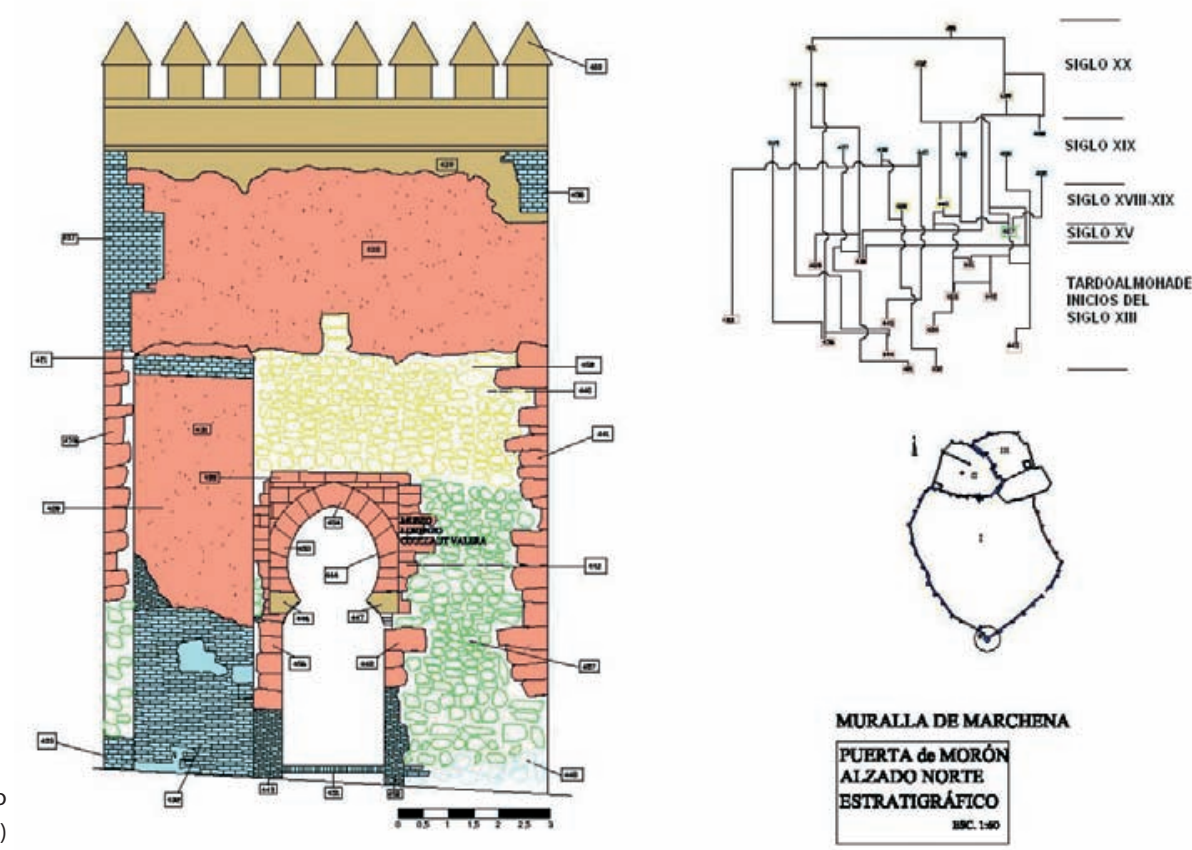

Los Cuatro Cantillos (recinto de la Madina)
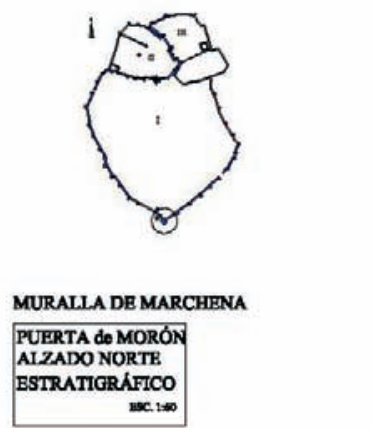

\section{Puerta de Morón (Fig. 15)}

\section{PROCESO 3. Primer período tardoalmohade}

Una de las puertas principales del recinto amurallado de Marchena de época tardoalmohade era aquella que conectaba la medina con el camino a través del cual se llegaba a la ciudad vecina de Morón de la Frontera, de ahí el nombre de puerta de Morón, también conocida actualmente por los propios habitantes del municipio como "Los Cuatro Cantillos».

Fue un acceso acodado con un carácter cerrado y militar, al que se accedía desde la ciudad extramuros a través de un arco de herradura apuntado y enmarcado en un elaborado alfiz de cantería (U.E. 444), que se encuentra un tanto modificado del aspecto que presentaría en origen. Tanto el arco, como el despiece de sus dovelas (U.U.E.E. 453, 454), el alfiz (U.E. 445) y todos los sillares cuadrangulares (U.U.E.E. 442, 443, 456) y ladrillos (U.E. 455) que lo encuadran, forman parte de la última etapa almohade, a excepción de los salmeres en nacela (U.U.E.E. 446, 447) que conforman la herradura, que están claramente repuestos.

En cuanto a la otra puerta del torreón, aquella que daba acceso a la medina y que se ubica en el alzado Este, se presenta mediante un doble arco de ladrillos rebajado, siendo únicamente originales las jambas del arco más externo, conformadas por sillares perfectamente cortados y colocados. Por tanto, la anchura de la puerta sigue siendo la misma que en origen, pero la rosca del arco ha sido reformada.
Por encima de esta puerta, se conservan dos cajones de tapial original, uno de ellos cortado, y sobre los mismos, una línea de ruptura los separa del resto de la fábrica de

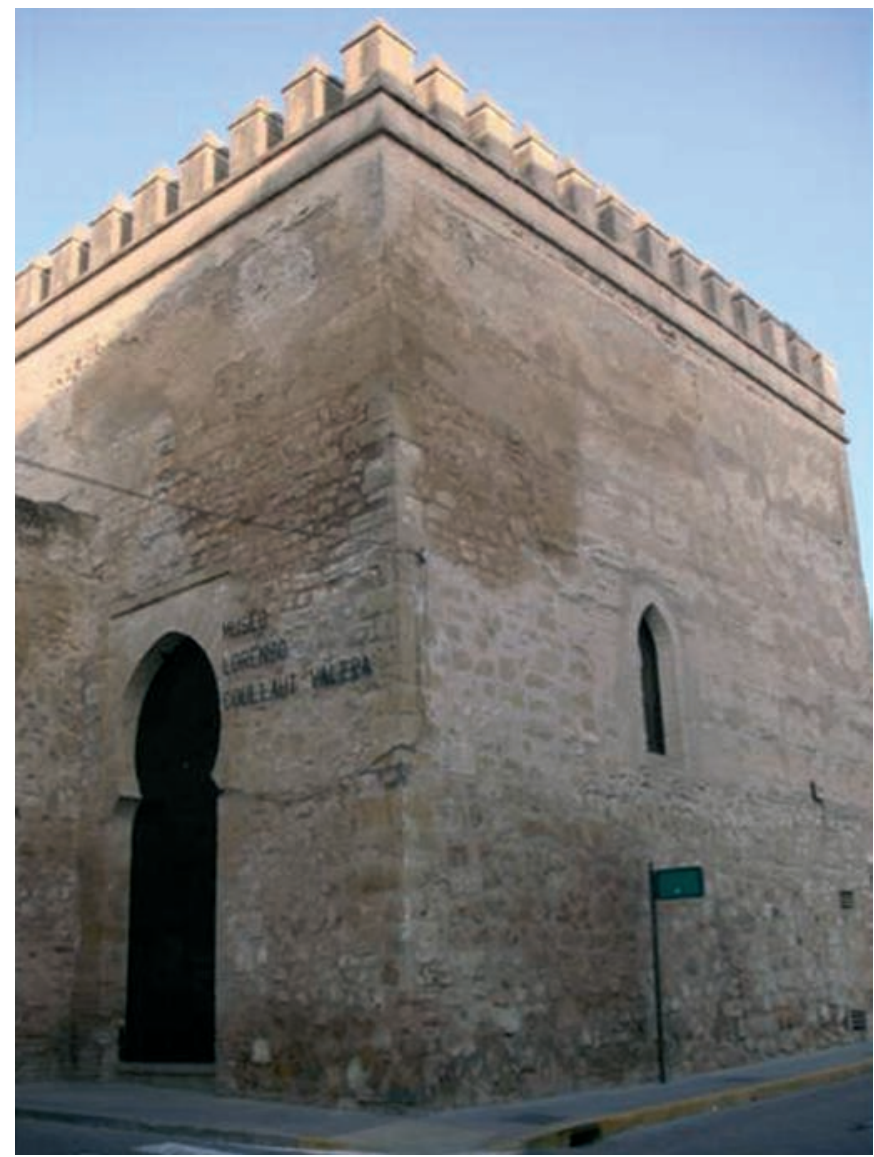

Fig. 16. Imagen actual de los alzados norte y oeste de la Puerta de Morón 
tapial que emerge tras los restos de un enjabelgado contemporáneo.

La técnica constructiva es la misma que la del resto de muralla tardoalmohade, es decir, a base de cajones de tapial, observables en cada uno de sus cuatro frentes (U.U.E.E. 403, 438, 460, 483). Con respecto al alzado sur, es el que mejor conserva la fábrica de tapial, donde se observan casi nueve cajones, incluso en algunos puntos se aprecian las juntas verticales que los unen. No obstante, en origen, es muy probable que fuese una construcción unitaria en tapial, aunque su aspecto actual nos delata las continuas transformaciones que se han ido aconteciendo a lo largo de los siglos.

Las cadenas de sillares de las esquinas de los torreones se encuentran fragmentadas (Fig. 16). Son grandes sillares de piedra arenisca, trabajados de forma rectangular o cuadrangular que se colocan como refuerzo en las esquinas, apreciable en todos los alzados.

En cuanto al remate almenado original (U.E. 400), no se conserva resto alguno, tan sólo sabemos, por otros conservados en diversas partes de la cerca, que sería un tanto más alto y con los merlones más proporcionados que los que encontramos actualmente.

En definitiva, esta tipología de puerta abierta dentro de la propia torre, en cuyo interior se desarrolla el pasaje en recodo, era un sistema más económico que el de arco flanqueado por dos torres. No obstante, la eficacia no era menor, ya que la puerta de acceso se ubicaba en uno de los costados de la torre y no en su frente, que presentaría unas mayores dimensiones, por lo que esa zona quedaba completamente dominada por la terraza de la torre, o bien, por el adarve de la muralla contigua (TORRES BALBÁS, 1985, 618). Encontramos otros ejemplos en la alcazaba de Granada, como son la Puerta Nueva o la Puerta Monaita.

\section{Proceso 5. Fase inicial castellana. Reformas en el siglo XV} Es muy probable que la bula papal otorgada en 1430 para la reedificación de gran parte de la muralla favoreciera igualmente a este sector, que se encontraba bastante deteriorado con motivo de las agitaciones bélicas acontecidas en Marchena. Se efectuaron una serie de reformas y añadidos a lo largo de todo el sistema defensivo islámico, reconstruyendo los lugares que habían quedado arrasados y reforzando aquellos puntos más débiles con fábrica de mampuesto y cantería, y con la construcción de torreones semicirculares.

En este caso, encontramos un gran zócalo de mampostería careada (U.E. 457) ${ }^{31}$ distribuido por cada uno de

${ }^{31}$ Que en algunos casos, dada las grandes dimensiones que presenta, parece sillarejo. los cuatro alzados y que encaja perfectamente con el resto de elementos originales existentes (cadenas de sillares y jambas de puertas). A su vez, se entremezcla con una serie de parcheados de mampostería y retacados de ladrillos correspondientes a una etapa muy posterior.

Pensamos que estos grandes zócalos pueden pertenecer al siglo XV, es decir, al momento en el que hemos encuadrado las transformaciones ya citadas que se desarrollaron en el entorno de la puerta de Sevilla, así como la construcción de una serie de torreones semicirculares distribuidos por todo el perímetro amurallado, observándose en todo ello una fábrica constructiva homogénea.

\section{PROCESOS 7 y 8 . Reformas en los siglos XVIII Y XIX}

No podemos aseverar rotundamente si fue durante el siglo XVIII o bien ya en el siglo XIX, el momento en el que se produjeron una serie de reformas que afectaron notablemente el aspecto externo de este torreón. Sin duda, la más llamativa fue la apertura de una serie de vanos de entrada o ventilación para diversos negocios en su interior, que cambiarían con el tiempo, incorporados en el zócalo de mampuesto, que a su vez quedó encubierto por una gruesa capa de pintura que homogeneizaba su aspecto, junto con la jabelga que recibió toda la zona intermedia y alta ocultando la primitiva fábrica de tapial. Es por ello, que hasta la segunda mitad del siglo $\mathrm{XX}$, este monumento, que además había perdido todo su remate almenado, aparecía aislado y sin ese carácter militar y fortificado del que en su día hizo gala, y que años después recuperará.

En el siglo XIX, se llevaron a cabo bastantes destrucciones en el trazado amurallado. Una de las más significativas fue la demolición de la puerta de Osuna, de la que tan sólo conservamos uno de los dos torreones que poseía. La puerta de Morón tenía adosada un lienzo de muralla (U.E. 421) que conectaría con una torre cuadrangular la cual se encontraba en lo que es hoy día la plaza actual del ayuntamiento, donde en la centuria siguiente, en 1906, aprovecharon la base de la susodicha torre para levantar la conocida "Torre del Reloj»" (ALCAIDE, 2003, 89).

Durante estos años, todo aquello que supusiera un entorpecimiento para el crecimiento y desarrollo de la ciudad sería desmantelado sin excepción alguna. Tal es el caso del lienzo amurallado al que hemos hecho mención, el cual, para poder abrir la calle San Francisco y por la que

\footnotetext{
32 Que también fue demolida a mediados del siglo XX para la construcción del
} nuevo ayuntamiento. 
pudieran pasar los carruajes holgadamente, fue cortado y destruido casi al completo, dejando tan sólo un pequeño vestigio de su grandiosidad, y que encontramos hoy bastante fragmentado y modificado.

Es por ello que este torreón adquiere, desde estos momentos, un carácter aislado, presentándose como un nuevo hito monumental junto con la puerta de Sevilla ${ }^{33}$.

\section{PROCESOS 8 y 9. Reformas en los siglos XIx y primera mitad del $x x$}

Fueron muchas las alteraciones experimentadas en este torreón durante el siglo XIX. Por el tipo de ladrillo empleado en numeras zonas de cada uno de los cuatro alzados, pensamos que debe tratarse de una obra correspondiente a una etapa bastante moderna, concretamente a esta centuria o a los primeros años del siglo XX.

Pero además, existen una serie de retacados de ladrillos en las partes bajas de los ángulos. En aquellas otras zonas donde ha habido una pérdida de materia constructiva, como es el fragmento de lienzo amurallado (U.E. 421) cortado en el siglo XIX para incorporar la calle San Francisco, donde se aprecia un gran parcheado de ladrillos, $o$ en el alzado oeste, en una esquina y en el arranque del remate superior. Pero además, encontramos retacados en las jambas del arco de herradura (U.E. 444) (alzado norte), alargando el tamaño del arco al bajar un tanto el nivel del suelo, de ahí que localicemos, igualmente, un pequeño zócalo de un aparejo irregular de mampostería en los alzados norte (U.E. 448) y oeste.

Por estos años, es posible que se construyera el nuevo arco rebajado que se encuentra en el alzado este, en el que se aprovecharon las primitivas jambas de sillares del previo para construir uno nuevo de ladrillos. Pasando el pasaje de entrada, se construyó otro arco rebajado de ladrillos muy similar al anterior.

\section{Proceso 10. Segunda mitad del siglo xx. Reformas contemporáneas}

Durante el siglo XX se realizaron una serie de transformaciones muy significativas en este torreón, las cuales le otorgaron una nueva imagen más parecida a la que pudiera tener en origen que la que presentaba a comienzos de esta misma centuria.

Gracias a una fotografía de los años 50, podemos hacernos una idea del aspecto que tenía antes de iniciar su transformación en la segunda mitad del siglo XX.

${ }^{33}$ La cual se salvó de las citadas destrucciones del siglo XIX gracias al hecho de haber perdido su importancia y carácter funcional.
Los cambios más radicales los experimentó el alzado oeste, donde había una serie de vanos (dos puertas, dos ventanas y un balcón) que daban acceso a varios comercios que se encontraban en el interior del torreón. Éstos rompían la primitiva fábrica de mampuesto que estaba debajo de un zócalo de pintura, el cual se decidió quitar tras picar todo ese frente y el del alzado sur. Con respecto a los vanos, las dos ventanas y una de las puertas se taparon con unos parches de mampostería, y la otra puerta que quedaba, ubicada muy cerca de la esquina de unión entre el alzado oeste y el sur, fue cegada unos años después con un aparejo parecido. El balcón era un arco apuntado de ladrillos que tenía acceso al exterior y se encontraba protegido con una barandilla metálica. La solución fue dejar el arco y quitar la baranda. Todas estas modificaciones han dejado una clara impronta en el lienzo, al apreciarse una fábrica distinta a la de origen.

Hacia 1960, se quitó el matacán que poseía, liso y sin merlones, pero que podría ser el antecuerpo, algo modificado, del primitivo cuerpo de merlones piramidales. Se construyó un nuevo remate almenado con fábrica deladrillos y recubierto de mortero de cemento con un antecuerpo más pequeño y a ras con el lienzo, el cual poseía un doble encintado de ladrillo, pero cuyos merlones eran algo desproporcionados en comparación con otros originales conservados en diversos puntos de la muralla. Además, en el alzado sur es donde más claro se aprecia el corte del último cajón de tapial para meter dicho remate.

Hacia 1966, la Dirección General de Cultura eliminó parte de las edificaciones que tenía adosada el torreón en cuestión. De hecho, en el alzado este se conservan improntas de haber tenido algún tejado adosado.

El enjabelgado que cubría todo el lienzo de tapial, realizado en el último cuarto del siglo $\mathrm{xx}$, se deja ver en algunas zonas altas del torreón.

En la década de los 80 , se procedió a rehabilitar el interior, momento en el que se colocaron las cristaleras y las verjas de hierro en las puertas para que dieran luminosidad y protección a la exposición que alberga. Igualmente, se consolidaron las almenas y se saneó el pasillo de ronda de la muralla que se encontraba adosada al torreón por su costado este, para que las aguas pudieran evacuar.

\section{Puerta de Carmona y Torre del Oro (Fig. 17)}

\section{PROCESO 3. Primer período tardoalmohade}

El recinto de la Alcazaba se ubicaba en la zona norte de la población, en el promontorio de la Mota, un lugar privilegiado desde donde se controlaba todo el territorio. 


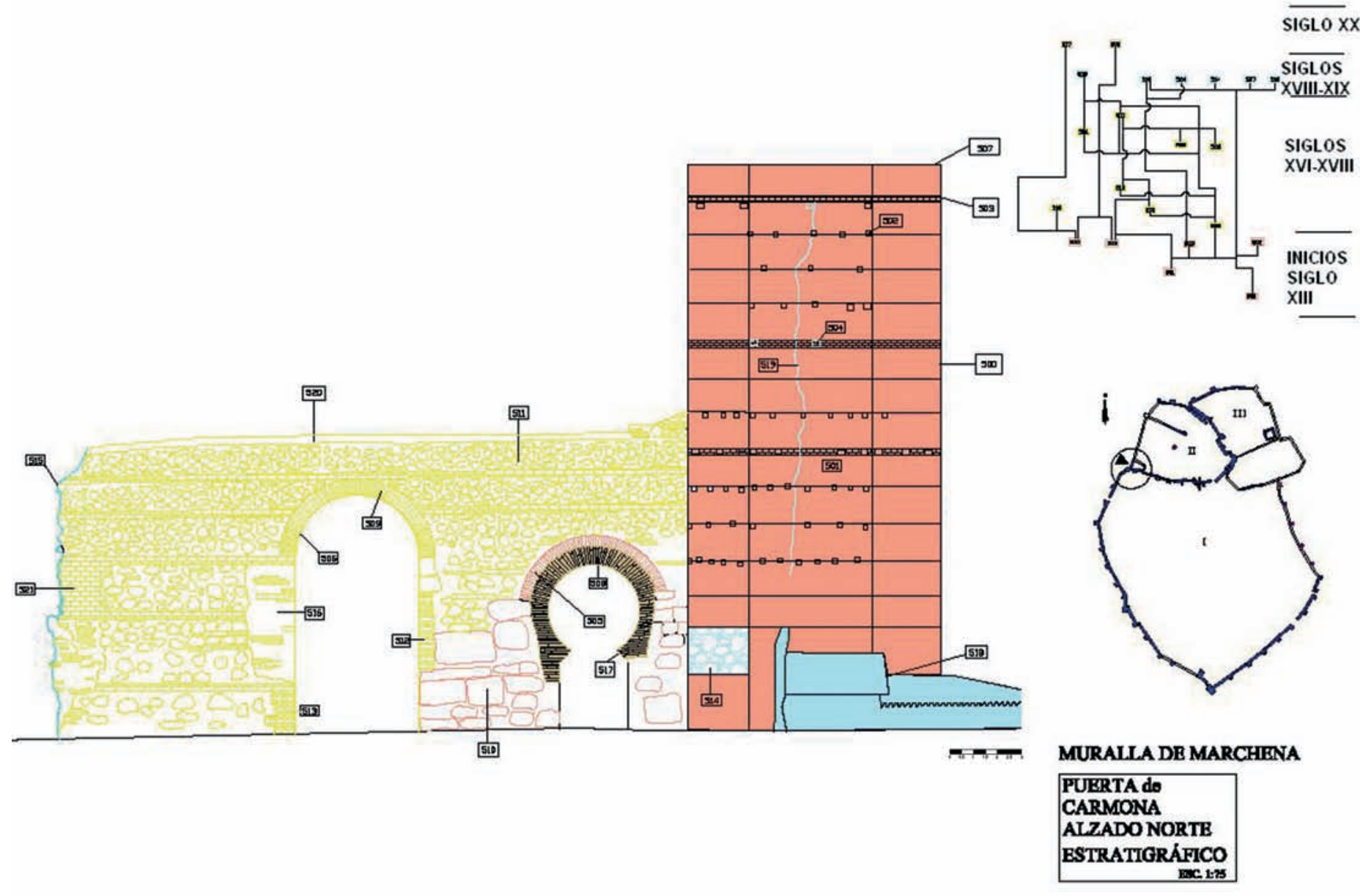

Fig. 17. Análisis estratigráfico de la Puerta de Carmona (recinto de la Alcazaba)

El hecho de encontrarse en una posición más elevada que el resto del cerco amurallado, ya suponía una mayor protección frente al ataque, y además, parte de su trazado se encontraba doblemente protegido por un antemuro o barbacana que tan sólo hemos documentado por el sector nororiental.

Al Norte, en el vértice entre dos recintos, el de la $M a-$ dina y el de la Alcazaba, se construyó una pequeña torre albarrana, conocida como «Torre del Oro» (U.E. 500), poligonal $^{34}$, realizada en tapial (U.E. 501), que se conserva hasta la altura del parapeto (U.E. 507), pero que en origen sería algo más elevada. Sobre ella se pueden ver los mechinales (U.U.E.E. 502, 540) en los que iban las agujas que utilizaron para la fabricación del tapial ${ }^{35}$, así como las líneas

\footnotetext{
34 Es de ocho lados irregulares, sin embargo, sabemos que esta irregularidad no es producto de ninguna reforma, sino su forma originaria, ya que las verdugadas de ladrillos se extienden por todos sus costados, a excepción del posterior, el único que ha podido ser algo reformado, pero no en exceso, ya que en él se abre la puerta primitiva de acceso al interior del torreón.

35 Aunque algunos de estos mechinales están muy deformados y se han convertido en grandes orificios para el albergue de las aves.
}

horizontales de unión de los cajones. Aún conserva tres verdugadas decorativas de ladrillos resaltadas y compuestas por cuatro bandas cada una (U.E. 503, 539). Parece ser una torre fundamentalmente maciza hasta el cuerpo superior, con una cámara superior abovedada de ladrillos y decorada con pintura de motivos geométricos, a la que se accede por unas escaleras superiores que se ubican en el camino de ronda de uno de los lienzos (U.E. 520) que se le adosan. Se ubicaba en un punto estratégico, algo escarpado, y desde donde tenían controlada toda la vega de Carmona.

Por su costado posterior salían dos lienzos de muralla, uno en dirección noreste (U.E. 520) (Fig. 17) y el otro en dirección sur (U.E.531) (Fig. 18) ${ }^{36}$. Ambos presentan un doble muro interno, compartido que hace ángulo con la parte posterior de la torre poligonal. Está realizado en tapial y aún se conserva en la actualidad, gracias a que las

36 Este lienzo que va en dirección sur, presenta una cara interna (en la que encontramos un doble muro compartido con la parte posterior de la Puerta de Carmona) que da al recinto de la Alcazaba y, otra externa (la figura 17) que da al recinto de la Madina. 
Fig. 18. Imagen actual de la Torre del Oro vista desde el interior del recinto de la Madina

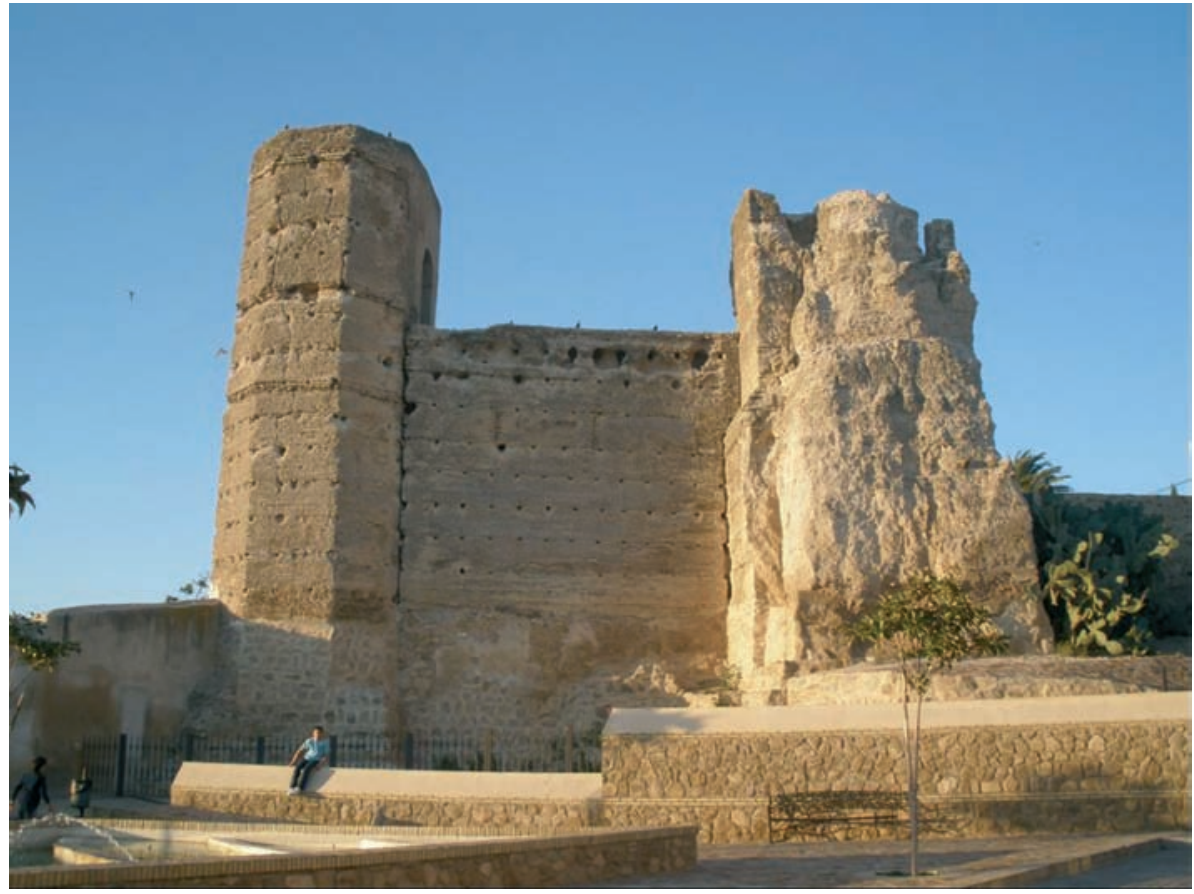

construcciones privadas que tenía adosadas fueron eliminadas en el último cuarto del siglo xx.

Con respecto al primer lienzo mencionado (U.E. 520), se trataba de una de las portadas principales en la que se ubicaba uno de los accesos a la alcazaba. La puerta estaba constituida por un arco de herradura (U.E. 505), del que nos ha quedado una imagen muy desvirtuada, producto de diversas reformas. En origen, el lienzo estaría construido en tapial, al igual que el resto del conjunto, sin embargo, hoy día presenta un grueso forro de una fábrica mixta incorporado siglos después.

Haciendo un ángulo recto y siguiendo una dirección sur, encontramos el muro de tapial (U.E. 531) muy fragmentado (Fig. 18). Tiene unas reducidas dimensiones, ya que su extremo norte se adosa a la torre poligonal y el sur a una torre cuadrangular (U.E. 530), sirviendo de doble pantalla protectora. Se construye por motivos de seguridad, para reforzar una de las zonas principales, el complejo del alcázar. De igual manera, deja ver sus mechinales y las juntas entre los cajones de tapial, aunque los tres cajones del remate superior pertenecen a un momento ligeramente posterior.

A continuación, encontramos una torre cuadrangular que presenta un estado deplorable y ruinoso, pero que aún insinúa la planta cuadrada que tendría en origen. Su fábrica es de tapial y por uno de sus lados, aún se pueden observar los cajones que la componían, coincidentes con los del lienzo. La torre estaba adosada al muro de tapial interior, anteriormente citado, que se corta en este punto, y del cual observamos algunos restos que salen por detrás de la torre.

Le sigue otro murete más bajo de mampostería realizado en el siglo $\mathrm{XX}$ y que se mete por detrás de otro fragmento de lienzo amurallado que aún se mantiene en pie. Este último conserva seis cajones de tapial, aunque los inferiores no se encuentran completos, y sus mechinales, pero el estado en el que persiste es preocupante por la gran cantidad de líneas de rotura estructural que se deben a la inestable cimentación y al desplome de gran parte del propio muro.

Todo este conjunto, debido al paso del tiempo, a las guerras que ha soportado desde su creación y a las condiciones atmosféricas, pues al estar en un lugar elevado ha sido siempre una de las zonas más expuestas de toda la población, ha sufrido un deterioro mucho más acelerado que en otros puntos de la muralla.

\section{Proceso 5. Fase inicial castellana}

La parte superior del lienzo (U.E. 531) presenta tres cajones realizados con un tapial diferente al resto de la fábrica, ya que se aprecian las improntas que ha dejado el barzón en el proceso de ejecución de la tapia. No obstante, no contamos con una analítica de su composición, tan sólo nos basamos en una clara diferencia visual.

Estos cajones se montan sobre la torre cuadrangular (U.E. 530), a la que además le colocan un gran parcheado 
de ladrillos y tapial, pero no queda a la misma línea que el resto de la torre, sino que se mete más adentro. La incorporación de este tapial posterior al original se explicaría por una gran destrucción sufrida en el sector con motivo, posiblemente, de alguna guerra.

Sabemos que en la localidad se produjeron una serie de acontecimientos históricos que perjudicaron gravemente la muralla: primero, la conquista de Marchena a manos cristianas en 1241; segundo, la invasión norteafricana de los benimerines en el último cuarto del siglo XIII; tercero, guerrillas fronterizas hasta el siglo XV; cuarto, la gran devastación provocada por Muhammad V en 1368; y por último, todos los terremotos soportados en la villa, los cuales provocaron enormes destrozos en el recinto murado.

Esta rara forma de la torre cuadrangular se hace intencionadamente, con el propósito de reparar un lienzo deteriorado con unos nuevos cajones de tapial, los cuales, para una mayor seguridad, consistencia y encastre, no se apoyan sólo en el lienzo primitivo, sino también en la torre.

\section{PROCESOS 6 y 7. Segunda fase castellana. Reformas en los siglos XVI-XVIII}

Durante el siglo XVI se efectúan una serie de reformas por el entorno del Portillo, con motivo de la boda de don Luis Cristóbal Ponce de León. Es muy probable que ese programa de reformas se extendiera por otros puntos nobles del recinto de la Alcazaba, como fue la puerta de Carmona.

Estaba constituida por un vano con forma de arco de herradura y dimensiones reducidas, motivo por el que decidieron construir junto a él otro portillo mayor, compuesto por un gran arco de medio punto (U.E. 506) con rosca de ladrillos ${ }^{37}$.

Puede que de este mismo período sea el forro ataluzado (U.E. 511) que recubre el lienzo (U.E. 520). Se trata de una fábrica mixta de mampostería con hileras de ladrillos que bien pudo pertenecer a este siglo XVI, puesto que aparece en otros lugares de Marchena como el Convento de Santa Isabel, aunque hay autores que lo encuadran, junto con el arco de medio punto, en el siglo XVIII (RAVÉ, 1993, 73).

\footnotetext{
37 Hemos propuesto como fecha de construcción del arco de medio punto el siglo XVI, apoyándonos en la documentación que aporta el Plan Especial de Protección del Conjunto Histórico de Marchena, basado, a su vez, en Morales y Sastre. Sin embargo, Ravé $(1993,73)$ propone como posible fecha de construcción el siglo XVIII, justificando que el nuevo arco se realizó fundamentalmente para dar salida desde el Palacio Ducal en dirección a Carmona.
}

\section{PROCESOS 7 y 8 . Reformas en los siglos XVIII-XIX}

Durante siglos este entorno ha permanecido abandonado, sin mantenimiento alguno, de ahí que a lo largo de los años se hayan ido perdiendo otras partes de la muralla que observamos en fotografías y ya no existen. Tal es el caso del lienzo (U.E. 520) que continuaba en dirección noreste y del que tan sólo nos queda un pequeño testigo en el que se hallan los dos arcos anteriormente comentados.

Como en otros sectores de la muralla, se comenzaron a adosar viviendas particulares reaprovechando sus muros, pero sin recibir un tratamiento de consolidación. Por ende, se hizo mayor el deterioro y aumentó el peligro de desplome. En este sentido, se abrieron grandes grietas (U.E. 519) en zonas como el costado norte de la Torre del Oro o en el alzado oeste, en cuyo lienzo se produjeron una gran cantidad de grietas verticales que arrancaban de los mechinales hacia abajo, todo ello evidenciando un grave problema estructural y de cimientos.

Es posible que en estos siglos se perdiera el remate almenado de la torre poligonal, que se presenta actualmente hasta la altura del parapeto (U.E. 507). Igualmente, se van deteriorando algunos de los mechinales, entre otras cosas, porque se convierte en el cobijo de aves, aumentando su tamaño.

Algunos socavones aparecidos en las partes bajas de la torre poligonal se taparon con parcheados de pequeños mampuestos (U.E. 514) que luego, en la segunda mitad del siglo XX, fueron rehechos. Lo mismo ocurre en la zona inferior del lienzo, donde aparecen unos grandes parches realizados con pequeñas piedras, los cuales reciben una recubrición de la que aún se conservan exiguos fragmentos.

\section{Procesos 9 y 10. Siglo XX. Añadidos contemporáneos}

La Puerta de Carmona y Torre del Oro, junto con los lienzos de todo su entorno, constituyen un área independiente al haber desaparecido la cerca que había en sus alrededores, potenciando ese carácter aislado y monumental.

Ha sufrido una enorme degradación debido a la acción de la erosión, a las construcciones que se le han ido adosando a lo largo de la historia, provocando un mal uso de sus lienzos, y a la evidente falta de mantenimiento.

En los años 80 se produce una desafortunada reforma del arco de herradura, al desvirtuar la posible organización original de la puerta, que en origen era de mayores dimensiones y algo más proporcionada, no teniendo en cuenta en 
dicha labor el enjarjado que parece haber tenido ${ }^{38}$. Aún se conservan las quicialeras primitivas y la línea de impostas la conocemos por fotografías de principios de siglo. Actualmente presenta una doble rosca de ladrillos (U.E. 508) y sus jambas corresponden con las originales, realizadas con materiales de acarreo (grandes sillares cuadrangulares) y mampuestos (U.E. 510).

Por esos años, se procedió a la consolidación urgente de la torre poligonal y a tapar unos socavones que poseía dicho torreón en la parte inferior y que podían provocar un derrumbe total del mismo sobre las viviendas que tenía adosadas.

Unos años después, con motivo de la redacción del Plan Especial de Protección del Conjunto Histórico de Marchena en 1995, se plantea la recuperación de todo este sector. Para ello, se suprimirán las construcciones que tenían adosados los lienzos y se consolidará la estructura.

En cuanto al área posterior del conjunto, no se puede acceder a la parte superior de la torre octogonal al conservarse, tan sólo, el tramo superior de la escalera externa.

A principios del siglo XXI se realizó una puesta en valor de toda la zona, remodelándose y adecuándose a mirador, para el que tuvieron que restaurar el alzado oeste del conjunto. Es por ello, que incorporaron a las zonas inferiores de todo este costado unos grandes montículos de mampostería irregular para que protegieran bien los cimientos de estos escasos restos.

Junto a esta labor, crearon un pequeño y bajo muro de mampuesto en el lugar del casi desaparecido lienzo de tapial del que quedan escasos vestigios tras la torre cuadrangular (U.E. 530). Sin embargo, el resto de los alzados de este conjunto, en concreto, su cara norte, donde están ubicados los dos arcos y que presenta una serie de construcciones cercanas que impiden su visibilidad, en origen era la fachada principal y hoy día está completamente olvidada, encontrándose rodeada de una prolífera vegetación, que apenas deja ver la mitad inferior de la estructura.

\section{CONCLUSIONES (Fig. 19)}

\section{Construcción de la muralla}

El cerco defensivo fue levantado ex novo ${ }^{39}$ por los almohades en el primer cuarto del siglo XIII, ya que según los

\footnotetext{
38 La puerta consta de una doble rosca de ladrillos, de la cual la más externa es la originaria. La reforma consistió en la construcción de otra rosca interna con una nueva disposición de los salmeres en nacela, presentando ahora unas dimensiones más reducidas que originalmente.

39 Sirva la consideración «ex novo» para refutar la hipótesis de que su alzado pudo haberse realizado tomando como base alguna construcción anterior.
}

resultados de nuestras excavaciones, junto con los de otras intervenciones anteriores, no hay signos de que la muralla se apoye sobre alguna estructura previa a la misma. En principio, estuvo conformado por dos recintos amurallados: el de la Alcazaba (donde se encontraba el alcázar) y el de la Madina (donde se desarrollaba la antigua ciudad), pero poco tiempo después, muy probablemente en una etapa almohade muy tardía o incluso cristiana muy inicial, se construyó el recinto secundario del Parque, también amurallado.

Con respecto al recinto de la Alcazaba, se ubicaba en el cerro de la Mota, el lugar más prominente de la localidad, desde donde se divisaban poblaciones cercanas. Sólo hemos documentado la existencia de barbacana en este recinto, puesto que varias excavaciones efectuadas en otros sectores del recinto de la Madina han constatado su ausencia.

El proceso de construcción de la muralla, al menos en el sector nororiental excavado, se lleva a cabo a través de una doble zapata construida sobre una serie de rellenos de tierra con fragmentos de cerámica muy diversa, sobre todo calcolítica y romana. Los constructores aprovecharon la pendiente del cerro de la Mota para incorporar una estructura en talud que se apoyaba directamente sobre la loma y que se hizo de forma paralela a los cimientos de la muralla, con la intención de crear un sólido refuerzo sobre el que poder construir una muralla firme. Luego se colmató el espacio intermedio mediante capas de tierra separadas por tongadas de cal hasta conformar el nivel de liza definitivo. Seguidamente se concluyó la muralla a la que se le incorporó un remate almenado, así como a la estructura ataluzada que adquirió un aspecto de barbacana y sirvió como tal.

Hemos documentado en este sector, que la barbacana se comenzó a levantar sobre un relleno de tierra arenosa que ofrecía un material lítico prehistórico y que incorporaba bastantes mampuestos. Esto último nos llevó a plantear la hipótesis de que pudiera tratarse de alguna construcción previa de la que no existen más testimonios materiales que los susodichos mampuestos. Por tanto, no tenemos constancia fidedigna de la existencia de alguna estructura anterior sobre la que se comenzara con todo el proceso de construcción tardoalmohade.

Al recinto se accedía por dos puertas: el arco del Tiro, que conectaba la ciudad con la alcazaba, y la puerta de Carmona, que conectaba el campo con la alcazaba. Esta última estaba flanqueada por una pequeña torre albarrana poligonal, conocida como Torre del Oro.

Por otra parte, el recinto de la Madina albergaba la 


\begin{tabular}{|c|c|c|c|c|c|c|c|c|c|c|}
\hline & $\begin{array}{c}\text { PROCESO 1 } \\
\text { Pre-almohade } \\
\text { (I) } \\
\text { Terreno } \\
\text { natural }\end{array}$ & $\begin{array}{l}\text { PROCESO } 2 \\
\text { Pre-almohade } \\
\text { (II) } \\
\begin{array}{l}\text { Derrumbes de } \\
\text { mampostería }\end{array}\end{array}$ & $\begin{array}{l}\text { PROCESO } 3 \\
\text { Primer período } \\
\text { tardoalmohade } \\
\text { Construcción de } \\
\text { la muralla }\end{array}$ & $\begin{array}{l}\text { PROCESO } 4 \\
\text { Segundo } \\
\text { periodo } \\
\text { tardoalmohade } \\
\text { Ampliación }\end{array}$ & $\begin{array}{c}\text { PROCESO } 5 \\
\text { Fase inicial } \\
\text { castellana } \\
\text { Reformas en los } \\
\text { siglos XIV-XV }\end{array}$ & $\begin{array}{l}\text { PROCESO 6 } \\
\text { Segunda fase } \\
\text { castellana } \\
\text { Reformas en el } \\
\text { siglo XVI }\end{array}$ & $\begin{array}{l}\text { PROCESO } 7 \\
\text { Reformas en el } \\
\text { siglo XVIII }\end{array}$ & $\begin{array}{l}\text { PROCESO } 8 \\
\text { Reformas en el } \\
\text { siglo XIX }\end{array}$ & $\begin{array}{c}\text { PROCESO 9 } \\
\text { Primera mitad del } \\
\text { siglo XX } \\
\text { Añadidos } \\
\text { contemporáneos }\end{array}$ & $\begin{array}{l}\text { PROCESO } 10 \\
\text { Segunda mitad del } \\
\text { siglo XX } \\
\text { Añadidos } \\
\text { contemporáneos }\end{array}$ \\
\hline $\begin{array}{c}\text { Muralla del } \\
\text { Recinto } \\
\text { de la } \\
\text { Alcazaba } \\
\end{array}$ & $\mathrm{x}$ & & $\mathrm{x}$ & & $x$ & $\mathrm{x}$ & & & & $\mathrm{x}$ \\
\hline $\begin{array}{c}\text { Barbacana } \\
\text { del } \\
\text { Recinto } \\
\text { de la } \\
\text { Alcazaba }\end{array}$ & $x$ & $x$ & $x$ & & $x$ & $x$ & & & $\mathrm{x}$ & $x$ \\
\hline $\begin{array}{l}\text { Sector del } \\
\text { Portillo } \\
\text { (Recinto } \\
\text { secundario } \\
\text { del Parque: } \\
\text { interior y } \\
\text { exterior) } \\
\end{array}$ & & & & $\mathrm{x}$ & $x$ & $x$ & & $x$ & & $x$ \\
\hline $\begin{array}{c}\text { Puerta } \\
\text { de Sevilla }\end{array}$ & & & & & $\mathrm{x}$ & $\mathrm{x}$ & $x$ & $x$ & & $x$ \\
\hline $\begin{array}{c}\text { Puerta } \\
\text { de Morón }\end{array}$ & & & $x$ & & $x$ & & $\mathrm{x}$ & $\mathrm{x}$ & $x$ & $x$ \\
\hline $\begin{array}{c}\text { Puerta } \\
\text { de Carmona }\end{array}$ & & & $x$ & & $x$ & $\mathrm{x}$ & $x$ & $x$ & $\mathrm{x}$ & $x$ \\
\hline
\end{tabular}

Fig. 19. Gráfico de equivalencias de los procesos por zonas de actuación

antigua ciudad islámica que correspondía con el actual barrio de San Juan y poseía una serie de puertas de entrada y salida que conectaba con las ciudades principales: Écija, Osuna, Morón, etc.

Existen dos tipos de puertas en este recinto. Por un lado, un solo torreón cuadrangular, al que se accedía desde la calle por uno de sus lados menores y luego, en su interior, realizando un giro en ángulo se llegaba al otro de sus lados menores, donde se encontraba un arco que comunicaba con la ciudad, tal es el caso de la puerta de Morón. Por otro, dos torres flanqueando la puerta, como es el caso de la desaparecida puerta de Osuna. Sin embargo, la puerta de Sevilla, que se creía islámica, la hemos encuadrado en un momento posterior, del que hablaremos a continuación, otorgando como posible puerta tardoalmohade unos muros y arquillo desaparecidos ya en el siglo $\mathrm{XIX}^{40}$, que se ubicaban por detrás del actual Arco de la Rosa y que podríamos relacionar con la primitiva ubicación del acceso.

Y por último, el recinto secundario del Parque, que se construye anexo al recinto de la alcazaba para su uso exclusivo (Fig. 20). Los resultados de las excavaciones ponen en evidencia la construcción de este recinto sobre un gran relleno de tierra arenosa, el cual cubría dos grandes formaciones abovedadas que presentaban una factura a base de bloques de piedras tendentes a la unión, muy similar a una factura ciclópea. Fue grande la expectación que provocaron estas estructuras y muchas las hipótesis

${ }^{40} \mathrm{Y}$ que conocemos gracias a unos planos encontrados en el A.H.M.M. Al respecto véase también: Ramos, 2006, 185, 213. planteadas con respecto a su origen. Por un lado, parecían antrópicas, puesto que en Marchena las formaciones geológicas presentan una cierta horizontalidad. Pero por otro, se creía en un probable origen natural, tras descartar la posible atribución como túmulo prehistórico, por no seguir una planta circular. La incertidumbre sobre la formación de estos montículos se vio agravado cuando apareció una tercera formación a mayor profundidad y con un aspecto mucho más trabajado, que reabrió el debate sobre su artificialidad. Ello nos llevó a desechar la idea de que pudiera tratarse de un sistema de doble fosa de alguna estructura previa a la muralla, por la forma en «V» que existía entre ambas formaciones, pero la aparición de la tercera estructura rompía dicho esquema, propiciando la necesidad de ampliar la campaña de excavación en ese sector de la ciudad para resolver definitivamente su aspecto y funcionalidad.

Se accedía al recinto mediante un "posible» ${ }^{41}$ arco de herradura que conectaba el campo con su interior, conocido como el Portillo. Sin embargo, debía tener otro acceso cercano que comunicara el recinto del Parque con el área de la alcazaba, del que no contamos con evidencia constructiva alguna. El Portillo es hoy día un arco apuntado que reutilizó los cimientos y parte de las jambas de sillares del posible arco de herradura anterior, respondiendo a una actuación post-almohade.

En definitiva, podemos decir que la muralla de Marchena se construyó en un mismo período, en la etapa final

41 Tan sólo hemos documentado los cimientos de un arco anterior, que por la cronología otorgada, suponemos que pudiera ser de herradura. 


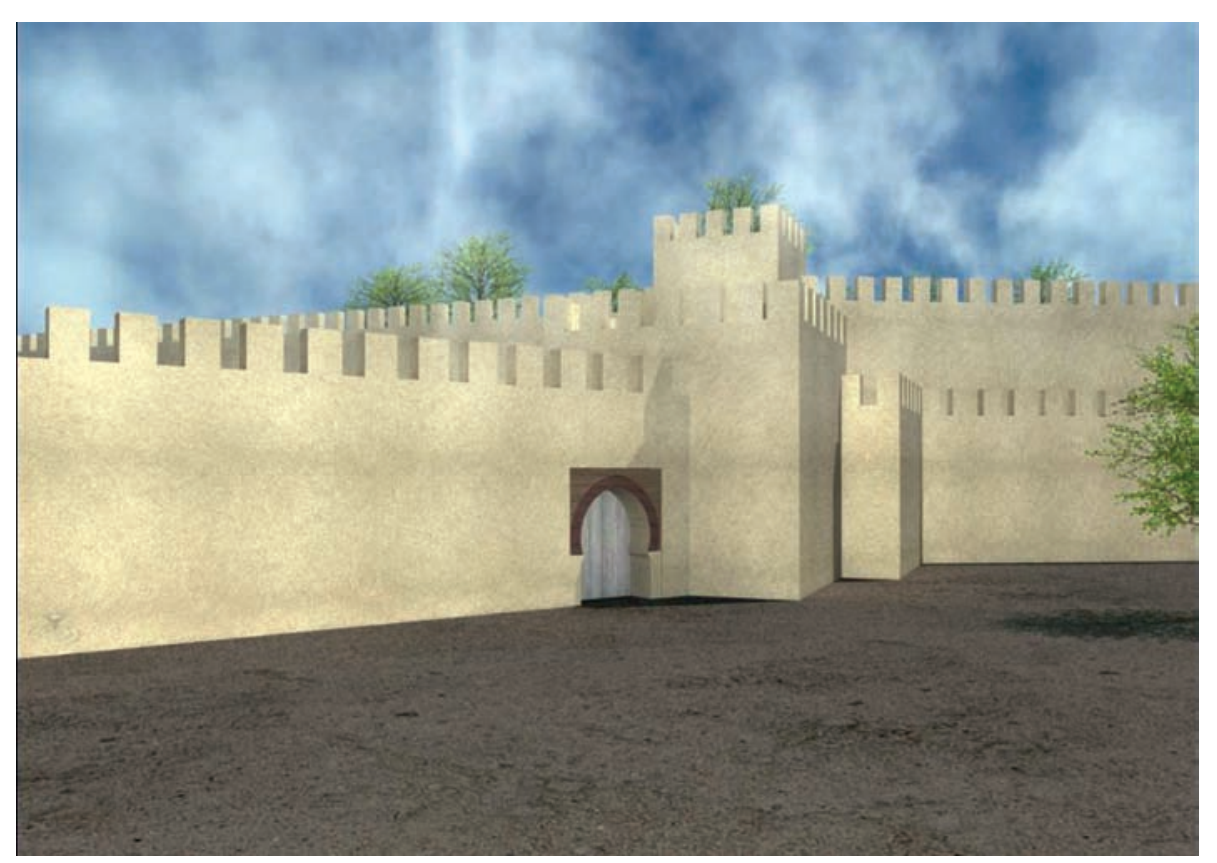

Fig. 20. Reconstrucción virtual del recinto del Parque (el Portillo) anexo al recinto de la Alcazaba en época tardoalmohade. Realizado por V. Pallarés de los almohades, y que utilizaron una fábrica homogénea a base de cajones de tapial. Se han encontrado similitudes, en cuanto a las dimensiones y composición, entre el tapial del recinto de la Madina y el utilizado en el del Parque, ambos de módulo bajo, mientras que el del recinto de la alcazaba era de módulo alto y de mayor calidad ${ }^{42}$.

\section{Reformas y añadidos posteriores}

En 1241 se produce la conquista cristiana de Marchena, momento que se aprovecharía para realizar alguna reforma. Tal pudiera ser el caso de la ampliación de los cajones de tapial que dejan ver las huellas del barzón en uno de los lienzos del entorno de la puerta de Carmona.

Sin embargo, esta localidad sufrió durante siglos diversas guerrillas fronterizas y una gran devastación en 1368 provocada por Muhammad V. Es por ello, que se hizo necesaria una urgente reparación de su cerco murado la cual vino de la mano de don Pedro Ponce de León en el siglo $\mathrm{XV}$, a través de una bula otorgada por el papa Martin V con la que se reedificó esas zonas más deterioradas. La reforma consistió en poner en marcha un programa constructivo de torres semicirculares que se repartieron por todo el conjunto, así como la construcción de una nueva puerta de Sevilla, conocida actualmente como Arco de la Rosa ${ }^{43}$, y una

42 Probablemente por ser la muralla que protegía el punto neurálgico de la ciudad, donde se encontraban las personas más importantes, debía ofrecer una mayor protección y seguridad.

${ }^{43}$ Se adelantó la trama urbanística, forzándose el quiebro, y se creó una nueva puerta en forma de arco de herradura flanqueada por dos esbeltas torres cuadrangulares. Anexo a ella había un lienzo de mampostería y seguido una torre semicircular. La homogeneidad evidenciaba una misma mano de obra. probable reparación de los zócalos de la puerta de Morón. Todo ello exterioriza una misma fábrica constructiva: el mampuesto careado.

Posiblemente con esta bula se reformaron otros puntos de la muralla no documentado. Podríamos relacionar con este hecho la construcción del pavimento de guijarros del Portillo, exhumado tras las excavaciones y que fechamos en el siglo XV.

Marchena pertenecerá al señorío de los Ponce de León desde el siglo XIV, sin embargo, el máximo apogeo constructivo se producirá durante los siglos XV-XVI. Concerniente a este último, se producen algunas reformas fundamentalmente por el sector nororiental del recinto de la Alcazaba, ya que en 1544 se documenta la boda de don Luis Cristóbal Ponce de León, la cual justifica el arreglo de todo el área, incorporando contrafuertes en los lugares más debilitados, recubriendo con un enlucido todo el frente de muralla y torres, forrando con sillarejo aparejado la barbacana y recreciendo el almenado tanto de la barbacana como del Portillo. De todo esto, han llegado hasta nosotros escasos vestigios. Puede que por este mismo motivo se decidiera forrar también de mampuesto y ladrillos el lienzo en el que se inserta la puerta de Carmona (Fig. 21).

Sin embargo, son muchas las reparaciones que se han ido efectuando en los últimos siglos: apertura de vanos, adosamientos de viviendas, inserción del trazado amurallado en el urbanismo, etc. No obstante, debemos hacer una parada en el siglo XIX, momento en el que se acometen bastantes demoliciones en la cerca, por considerarse un entorpecimiento para el crecimiento urbano de la locali- 
Fig. 21. Reconstrucción virtual del recinto del Parque (el Portillo) anexo al recinto de la Alcazaba en el siglo xvı. Realizado por V. Pallarés

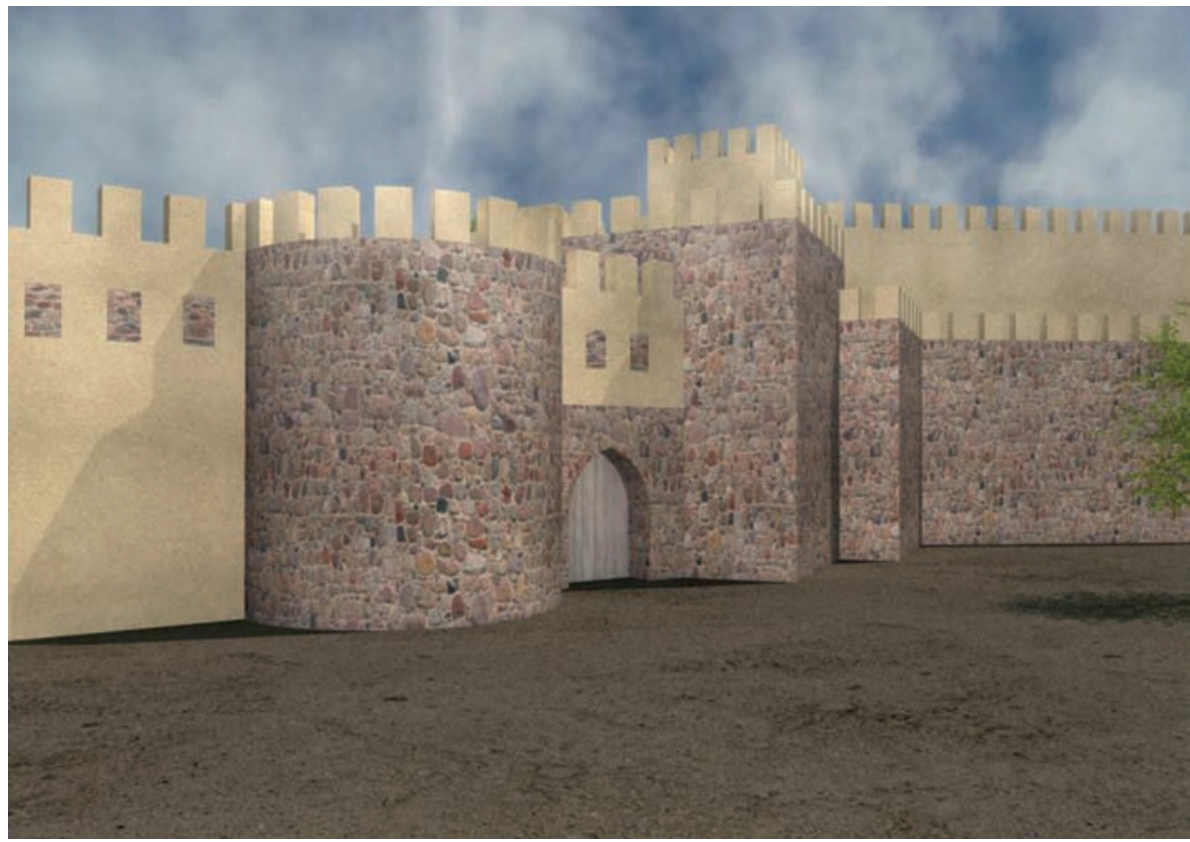

dad. Tal es el caso de la destrucción de la puerta de Osuna, de la que nos ha quedado una de las dos torres que la conformaban; la apertura de la calle San Francisco, para la que cortaron la muralla dejando un exiguo testigo adosado a la puerta de Morón; la apertura de la calle Zurbarán, para la cual destruyeron el lienzo amurallado que conectaba el recinto de la Madina con el de la Alcazaba; la demolición de la puerta de Écija, de la que no conocemos su ubicación exacta; y una destrucción parcial del recinto del Parque para incorporar la carretera comarcal que conduce a Carmona.

En el siglo XX se destruye, igualmente, una amplia zona de la muralla que llegaba hasta la calle San Francisco para la construcción del nuevo ayuntamiento. No obstante, este es un siglo lleno de reformas y añadidos. En el caso del Arco de la Rosa, eliminan la rampa terriza que tenía la puerta por un acceso escalonado, destruyen los pórticos dedicados antaño a carnicerías y, en el siglo XX, a diversos comercios, y que se encontraban adosados a un lienzo de muralla, y reconstruyen el remate almenado (labor que amplían por otras zonas amuralladas). La puerta de Morón experimenta un cambio radical, ya que se elimina el zócalo pintado que se había incorporado años atrás, dejando relucir el mampuesto que poseía, posiblemente, desde el siglo XV. Se cegaron también con mampuesto las puertas y ventanas pertenecientes a comercios que se encontraban en su interior y se enjabelgó toda la mitad superior donde se encontraba el tapial original tardoalmohade. La puerta de Carmona y Torre del Oro experimentaron una urgente consolidación, al presentar graves problemas estructurales que, de lo contrario, podrían haber desembocado en un derrumbe, y se acondicionó como mirador, aunque tan sólo su cara oeste, dejando en abandono el resto. Y en el caso del entorno del Portillo, esta zona se dejó abandonada durante siglos. Únicamente se le incorporaron a uno de sus lienzos unas cuadras de crías de animales que desfavorecieron aún más su estado, para finalmente convertirse en una ruina con numerosos desprendimientos recubiertos de una prolífera vegetación.

En definitiva, la cerca urbana de Marchena presenta un buen estado de conservación ${ }^{44} \mathrm{y}$ es una de las pocas que han persistido en la provincia de Sevilla, gracias a las múltiples restauraciones que se han ido aconteciendo a lo largo de los siglos y al adosamiento de gran parte del urbanismo sobre sus muros, contribuyendo, por tanto, a su mantenimiento.

Hay zonas que han sido muy deformadas por la diversidad de transformaciones que han tolerado, tal es el caso de la puerta de Morón. Sin embargo, el Arco de la Rosa, uno de los mayores emblemas de la ciudad, a pesar de haber sido uno de los puntos que más restauraciones haya podido experimentar a lo largo de la historia, posiblemente por ubicarse en un punto clave, es sin duda el menos alterado, conservando en gran parte su fisonomía originaria.

Otros lugares, como la puerta de Carmona y Torre del Oro, han perdido gran parte de la estructura que los rodeaba, presentándose como hitos descontextualizados y con

\footnotetext{
${ }^{44}$ A excepción de algunas zonas ya comentadas.
} 
una ausencia notable de mantenimiento. Y por último, el Portillo constituye el ejemplo de zona olvidada y abandonada a la que se le ha relegado durante años su importancia histórica, y es actualmente el momento en el que se quiere rehabilitar unas ruinas que anuncian su derrumbe definitivo si no se actúa con brevedad y precisión.

\section{Bibliografía}

AlCAIDE, F. (2003): Marchena histórica y Monumental. Marchena.

AlejANDRE, J. y MARTín, J. (2008): “Caracterización de los tapiales del mirador almohade de la muralla de Marchena», Memoria Final de la intervención arqueológica preventiva en el Mirador Almohade de la Muralla de Marchena (Sevilla). Obra inédita.

Amores, F. et alii (1985): Inventario artístico de Sevilla y su provincia. Madrid.

AZUAR, R. (2004): «Las técnicas constructivas y la fortificación almohade en alAndalus», Los Almohades. Su patrimonio arquitectónico y arqueológico de AlAndalus. Sevilla, 57-74.

AA.VV. (1996a): Actas de las I Jornadas sobre Historia de Marchena. Marchena.

AA.VV. (1996b): I Congreso Internacional. Fortificaciones en al-Andalus. Algeciras.

AA.VV. (1997): Actas de las II Jornadas sobre Historia de Marchena. Marchena bajo los Ponce de León: Formación y consolidación del señorio (siglos XIII-XVI). Marchena.

AA.VV. (1998): Actas de las III Jornadas sobre Historia de Marchena. Marchena en la modernidad (siglos XVII-XVIII). Marchena.

AA.VV. (2001): Congreso de fortificaciones en el entorno del Bajo Guadalquivir. Alcalá de Guadaíra.

DoGLIONI, R. (1988): «La ricerca sulle strutture edilizie tra archeologia stratigrafica e restauro architettonico", Archeologia e Restauro dei Monumenti. Firenze, 223-246.

DOMínguEZ, E. (2007): «La huella olvidada: Arqueología y territorio de la Marchena andalusí», Arqueología en Marchena. El poblamiento antiguo y medieval en el valle medio del rio Corbones. Sevilla, 189-242.

Ferrer, E. (2007, coord.): Arqueología en Marchena. El poblamiento antiguo y medieval en el valle medio del rio Corbones. Sevilla.

FourNiER, J. (2008): «Estudio ceramológico de la excavación efectuada en el entorno de El Portillo", Memoria Final de la intervención arqueológica preventiva en el Mirador Almohade de la Muralla de Marchena (Sevilla). Obra inédita.

GARCÍA, M. (1996): «Marchena: la villa señorial y cristiana (siglos XIII-XV)», Actas de las I Jornadas sobre Historia de Marchena. Marchena, 73-91.

GARCÍA, M. (2005): La campiña sevillana y la frontera de Granada (siglos XIII-XV): estudios sobre poblaciones de la Banda Morisca. Sevilla.

GARCÍA, E. y DÍAZ, R. (1997a): «Excavación arqueológica de urgencia en la calle Zurbarán n. 2 (Marchena, Sevilla)», Anuario Arqueológico de Andalucía 1997. III, 610-612.
García, E. y DÍAZ, R. (1997b): «Excavación arqueológica de urgencia en la calle Carrera no 35 (Marchena, Sevilla)», Anuario Arqueológico de Andalucía. III, 613-619.

Graciani, A. y TABALES, M.Á. (2003): «Typological observations on tapia walls in the area of Seville. $11^{\text {th }}-19^{\text {th }}$ centuries». Primer Congreso Internacional de Historia de la Construcción. Madrid, 1093-1106.

Graciani, A. (2008): «Estudio de las fábricas del Mirador Almohade de la Muralla de Marchena", Memoria Final de la intervención arqueológica preventiva en el Mirador Almohade de la Muralla de Marchena (Sevilla). Obra inédita.

IZQUIERDO, R. (1996): "Las alcazabas en al-Ándalus: sentido y funciones», I Congreso Internacional. Fortificaciones en Al-Ándalus. Algeciras, 103-110.

Millán, J. (1996): "Protohistoria de Marchena y su entorno», Actas de las I Jornadas sobre Historia de Marchena. Marchena, 17-35.

PARENTI, R. (1988): "La techniche di documentazione per una lettura strattigrafica dell'elevato", Archeologia e restauro dei monumento (A cura di Ricardo Francovich). Firenze, 249-279.

Ramos, M. (2006): «La visión de Marchena entre dos siglos. Grabados, planos e imágenes", Actas de las X Jornadas sobre Historia de Marchena. Marchena a través de la imagen. Diez años de historia local (1995-2004). Marchena, 177230.

Ravé, J.L. (1993): El Alcázar y la Muralla de Marchena. Marchena.

Salazar de Mendoza, P. (1620): Crónico de la excelentíssima casa de los Ponces de León. Toledo.

TABAles, M.Á. (1997): «La arqueología en edificios históricos. Propuesta de intervención y análisis global a través de la experiencia sevillana», Boletín del Patrimonio Histórico Andaluz, 20, 65-81.

TABALES, M.Á. (1998): Arqueología en edificios históricos de Sevilla: una propuesta de intervención. Tesis doctoral (inédita). Sevilla.

TABALES, M.Á. (2000): «Algunas reflexiones sobre fábricas y cimentaciones sevillanas en el período islámico». III Congreso Nacional de Historia de la Construcción, II. Sevilla, 1077-1089.

TABALES, M.Á. (2002): Sistema de análisis arqueológico de edificios históricos. Sevilla.

TABALES, M.Á. (2002a): «Arqueología y rehabilitación en Sevilla. Desarrollo metodológico y práctico», Arqueología de la Arquitectura 1 (2002), 193-206.

TABALES, M.Á. (2004): «Algunas notas sobre fábricas murarias almohades en Sevilla", Los Almohades. Su patrimonio arquitectónico y arqueológico de AlAndalus. Sevilla, 75-90.

TERnero, R. (2006): «La geología de Marchena y su relación con el poblamiento y la ocupación humana del territorio", Actas de las X Jornadas sobre Historia de Marchena. Marchena a través de la imagen. Diez años de historia local (19952004). Marchena, 41-81.

Torres Balbás, L. (1985): Ciudades hispanomusulmanas. Madrid.

VALOR, M. (2004): "Algunos ejemplos de construcciones defensivas almohades en la provincia de Sevilla», Los Almohades. Su patrimonio arquitectónico y arqueológico de Al-Andalus. Sevilla, 145-163.

Recibido: 15 septiembre de 2008 Aceptado: 13 de enero de 2009 